\title{
Extremotolerant fungi from alpine rock lichens and their phylogenetic relationships
}

\author{
Lucia Muggia $^{1,2} \cdot$ Antonia Fleischhacker $^{1} \cdot$ Theodora Kopun $^{1} \cdot$ Martin Grube $^{1}$
}

Received: 20 March 2015 / Accepted: 6 August 2015 / Published online: 22 August 2015

(C) The Author(s) 2015. This article is published with open access at Springerlink.com

\begin{abstract}
Fungi other than the lichen mycobiont frequently co-occur within lichen thalli and on the same rock in harsh environments. In these situations dark-pigmented mycelial structures are commonly observed on lichen thalli, where they persist under the same stressful conditions as their hosts. Here we used a comprehensive sampling of lichen-associated fungi from an alpine habitat to assess their phylogenetic relationships with fungi previously known from other niches. The multilocus phylogenetic analyses suggest that most of the 248 isolates belong to the Chaetothyriomycetes and Dothideomycetes, while a minor fraction represents Sordariomycetes and Leotiomycetes. As many lichens also were infected by phenotypically distinct lichenicolous fungi of diverse lineages, it remains difficult to assess whether the culture isolates represent these fungi or are from additional cryptic, extremotolerant fungi within the thalli. Some of these strains represent yet undescribed lineages within Chaethothyriomycetes and Dothideomycetes, whereas other strains belong to genera of fungi, that are known as lichen colonizers, plant and human pathogens, rock-inhabiting fungi, parasites and saprotrophs. The symbiotic structures of the lichen thalli appear to be a shared habitat of phylogenetically
\end{abstract}

Electronic supplementary material The online version of this article (doi:10.1007/s13225-015-0343-8) contains supplementary material, which is available to authorized users.

Lucia Muggia

lmuggia@units.it; lucia_muggia@hotmail.com

1 Institute of Plant Sciences, University of Graz, Holteigasse 6, 8010 Graz, Austria

2 Department of Life Sciences, Università degli Studi di Trieste, Via Valerio 12/2, 34128 Trieste, Italy diverse stress-tolerant fungi, which potentially benefit from the lichen niche in otherwise hostile habitats.

Keywords Black fungi $\cdot$ Endolichenic $\cdot$ Symbioses · Lichenicolous $\cdot$ Life style $\cdot$ Phylogeny

\section{Introduction}

Bare rock surfaces provide little comfort to life. They are poor sources of nutrients and are constantly exposed to a variety of extremes in abiotic conditions. Variations in surface temperatures and water availability can occur at very short time spans and be the source of diverse stresses (Zakharova et al. 2013; Sterflinger et al. 2012), and with enormous amplitudes. In addition, direct exposure to full sunlight includes a threatening level of energy-rich ultraviolet wavelengths. Not many organisms can cope with such surfaces at this "edge of life", thus these surfaces are colonized by specialists with particular adaptations (Selbmann et al. 2005, 2013; Onofri et al. 2007; Marzban et al. 2013). In fact, some fungal lineages, which are known as "black fungi" or "microcolonial fungi" are among the most stress-resistant eukaryotic organisms on Earth and can occur at considerable diversity on rocks (Ruibal et al. 2005, 2009). The adaptations of these rockinhabiting fungi (RIF) include pleomorphic growth, efficient osmolyte management, melanin production, biofilm formation, and survival in cryptobiotic stage (Gostincar et al. 2010, 2011).

Black fungi do not form a monophyletic lineage but are members of Dothideomycetes and Chaetothyriomycetidae (Gueidan et al. 2008; Ruibal et al. 2009) which evolved during periods of dry climate in the late Devonian and middle Triassic, respectively (Gueidan et al. 2011). At approximately the same time scale, the symbiotic association whereby a 
fungus shelters microscopic algae or cyanobacteria in exchange for fixed carbon and nitrogen helped to ameliorate nutrient deficiencies on rocks. The lichen symbiosis was this key innovation in the evolution of fungi and lichenized mycobionts have since evolved and diversified (Lutzoni et al. 2001; Hawksworth 2015). Particularly, in alpine altitudes where conditions prevent the development of higher plants, lichen thalli express their phenotypic and phylogenetic diversity and shape the landscapes with colorful mosaics on rock surfaces.

In such variably stressed situations, black fungi and lichens can occur side by side on rock, and black fungi also colonize asymptomatic lichens, especially in arid situations (Harutyunyan et al. 2008). Harutyunyan et al. (2008) showed that black fungi may opportunistically infect lichens, but do not cause damage to their host thalli. Some of the fungi resemble hyphomycetous lichenicolous fungi. However, most lichenicolous fungi have a host specific occurrence and are recognized by their phenotypic symptoms and their sexual or asexual spore-producing structures (Hawksworth 1979; Lawrey and Diederich 2003). It is not known whether black fungi, cryptically colonizing lichen thalli, are directly in contact with the photobiont to obtain nutrients. Some studies, however, suggest that black fungi indeed have some affinity to microscopic algae (Brunauer et al. 2007; Gorbushina et al. 2005). Arnold et al. (2009) also used micro-dissection followed by surface sterilization to show that more culturable fungi were associated with the algal layer compared to the medulla and cortex.

In this study, we conducted a comprehensive sampling of saxicolous lichen species (as reported in Fleischhacker et al. 2015), including samples infected by symptoms-developing lichenicolous fungi from different sites of an alpine range, above the tree-line. We prepared culture isolates of the fungi and produced sequence data for phylogenetic analyses. With these we aimed at answering the following questions: i) are there patterns of co-occurrence among cryptic, black extremotolerant fungi, symptomatic lichenicolous fungi and lichen mycobionts?; ii) are lichen-associated fungal communities structured by mycobiont host? ; iii) what is the phylogenetic placement of the isolated strains?

\section{Material and methods}

Sampling Lichen thalli were collected on the Koralpe mountain range in the southeastern rim of the Austrian Alps, between the states Styria and Carinthia. The sampling was carried out as in Fleischhacker et al. (2015). Ten collection sites (plots), each further divided into 3 subplots, were selected in alpine habitat, above the timberline, ranging between 1800 and $2100 \mathrm{~m}$ a.s.l., and are characterized by big boulders and cliffs of homogeneous size of siliceous-schist/ gneissic rocks separated by wide areas of pastures or dwarf shrub formations. Here winds, in particular from South and West, reach speeds over $120 \mathrm{~km} / \mathrm{h}$ and the annual temperature averages $0-5{ }^{\circ} \mathrm{C}$ (http://www.umwelt.steiermark.at/cms/beitrag/10023583/ 25206/). In winter, rocks can remain covered by wind-pressed snow and ice for several weeks; alternatively, in summer the south-exposed rock surfaces receive intense solar radiation.

In these sites, boulders' surfaces are almost entirely colonized by crust-forming (90\%), foliose and fruticose $(10 \%)$ lichens. Crust-forming and foliose lichens were selected for the culture isolation experiment: (i) crustose thalli are composed by contiguous islands of thallus (areoles) which tightly adhere to the substrate with their entire lower surfaces; (ii) foliose thalli adhere only partly to the substrate by a central holdfast (umbilicus) or by root-like appendices (rhizines). About $10 \%$ of the lichen thalli in this region are infected by lichenicolous fungi (Fleischhacker et al. 2015). For the isolation of lichenicolous and extremotolerant fungi we selected multiple lichen thalli of different species visibly infected by different species of symptomatic lichenicolous fungi (Tables 1, 2, S3). In doing so, we aimed at including a comprehensive survey of the different lichenicolous fungus-lichen host associations occurring in the area. Within the same subplot, we selected up to four different symptomatically infected thalli. These were either lying close to each other or lying apart up to $50 \mathrm{~cm}$. The lichen thalli were sampled together with their substratum by chiseling the piece of rock. We sampled on both horizontal and vertical positions and at different expositions.

Culture isolation A total of 130 lichen samples, comprising 25 different lichenicolous fungus-lichen host associations, were selected for culture isolations. Thallus areoles or lobes presenting lichenicolous fungal infections were removed with a sterile razor blade and put into an Eppendorf tube. The isolation protocol followed Yamamoto et al. (2002). The pieces, about $2 \mathrm{~mm}^{2}$, were washed three times for 15 minutes in distilled sterile water on a shaking bath, followed by a 30 minutes washing step with $500 \mu \mathrm{l}$ of 1:10 dilution of Tween 80 to remove the possible external contaminations of bacteria and yeast (Bubrick and Galun 1986). A final washing step was carried out twice in distilled sterile water for 15 minutes. The clean fragments were dissected under the stereomicroscope using a sterile razor blade and single pieces were picked with a sterile needle, moistured with distilled sterile water, and transferred into agar tubes. In order to promote the growth of different fungi we inoculated the dissected fragments on six different media: Trebouxia Medium (TM, Ahmadjian 1967), Malt Yeast Extract Medium (MY, Ahmadjian 1967), Lilly and Barnett's Medium (LBM, Lilly and Barnett 1951), Potato Glucose Agar (PGA; Sigma), Dichloran-Glycerol 18\%-Agar (DG18; Sigma), Sabouraud-Agar (SAB; Sigma). Four tubes of the same medium were inoculated, resulting in a total of 24 tubes (inocula) for each original sample. The tubes were 


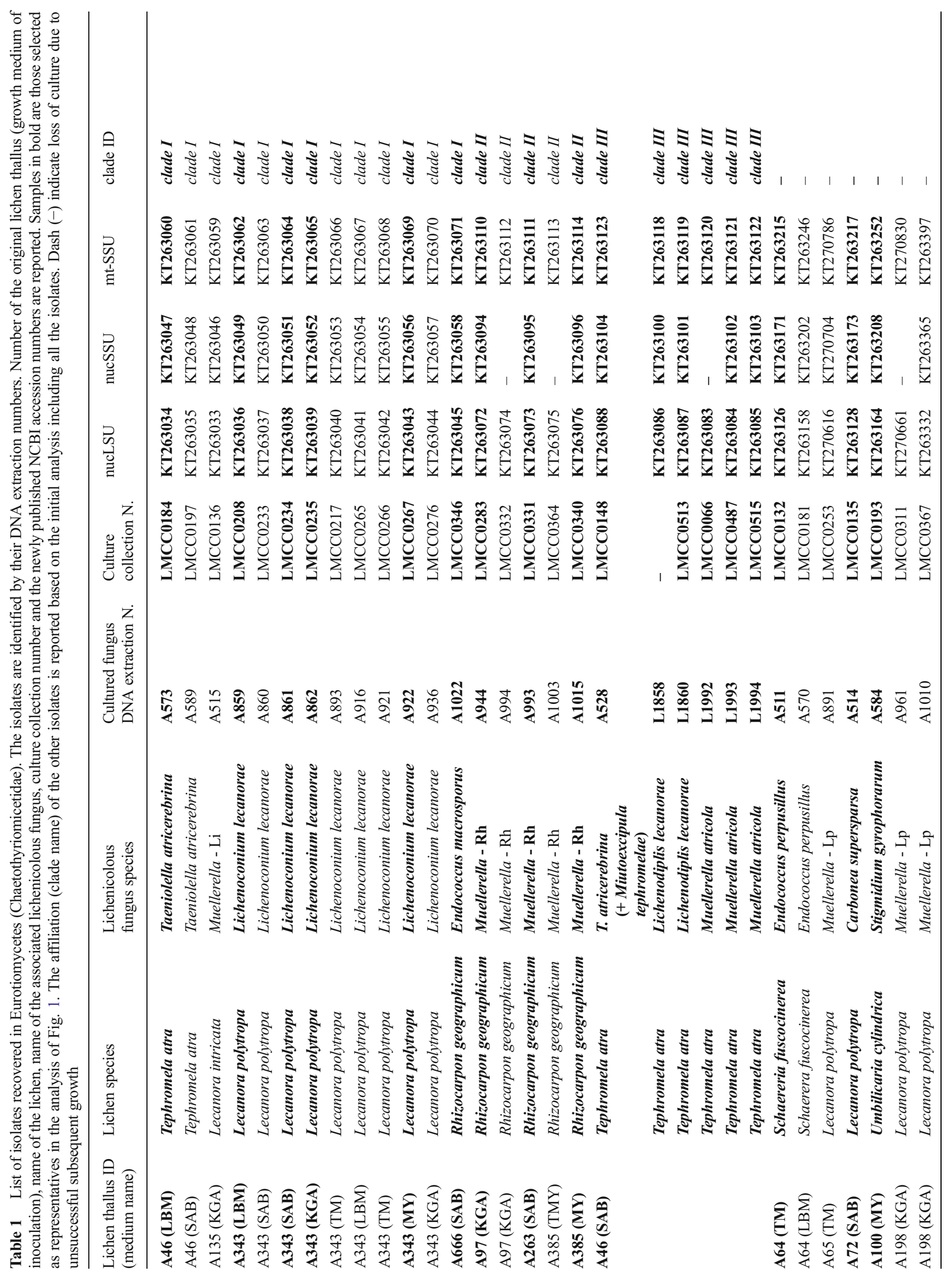




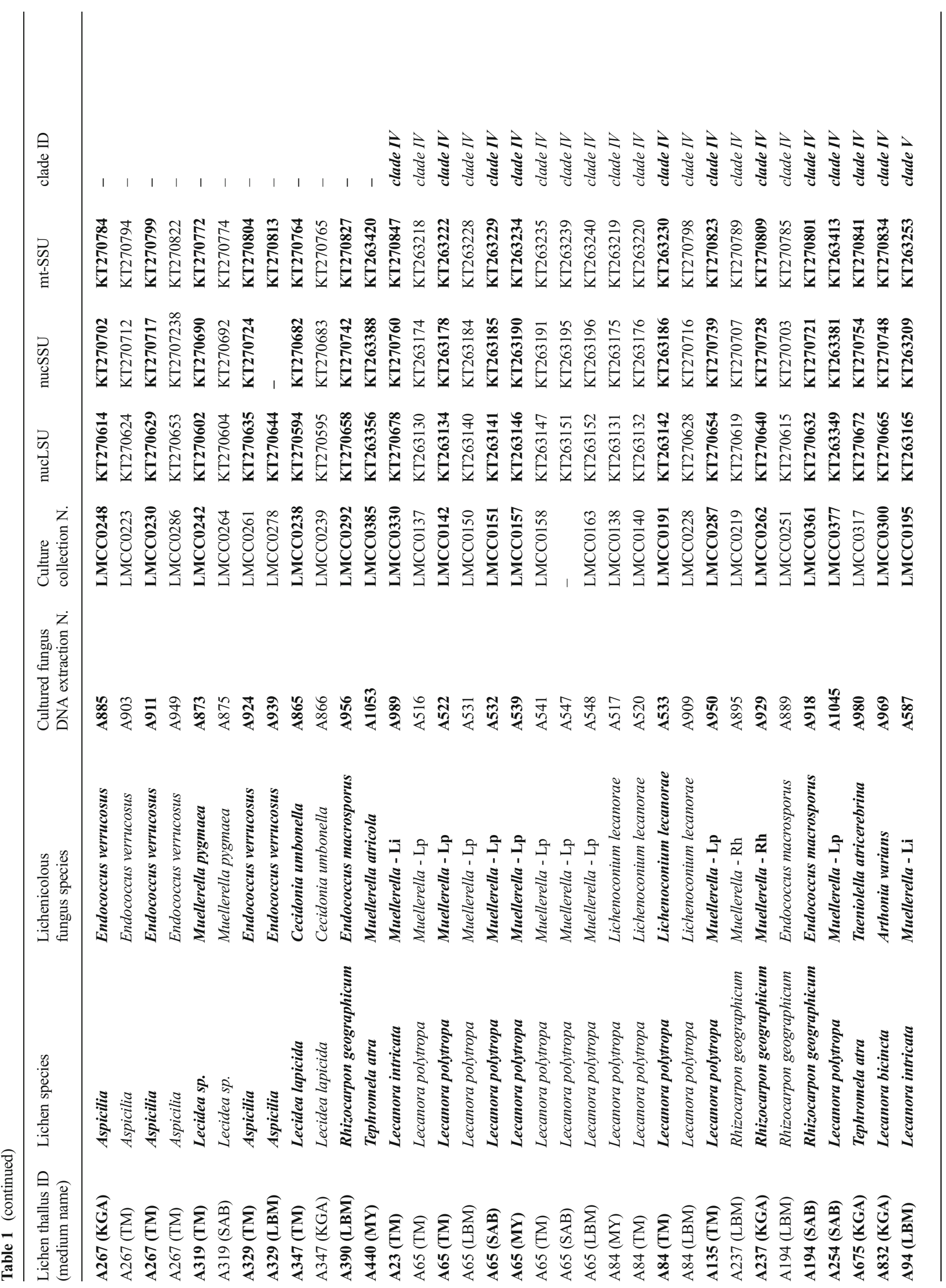




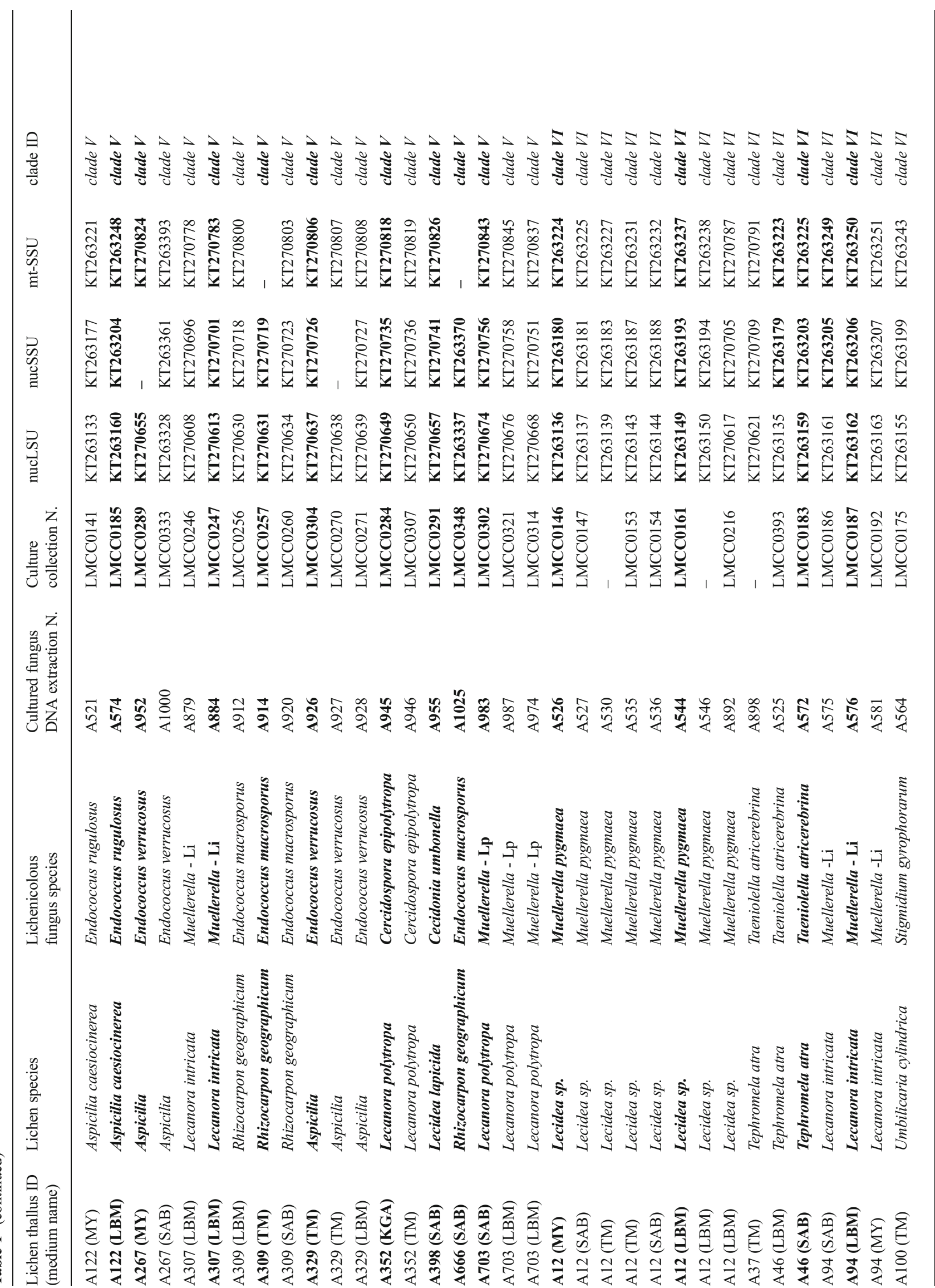


ค $\quad$ I

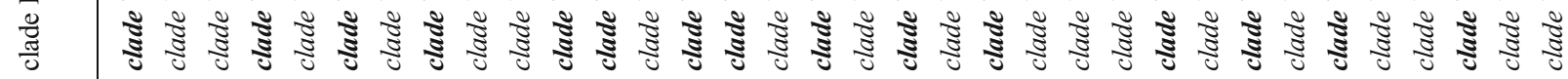

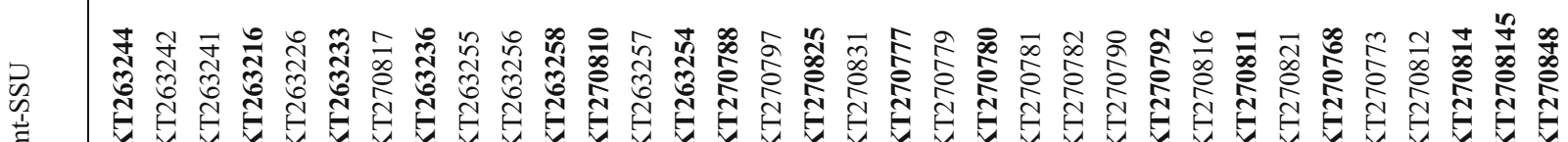
岸

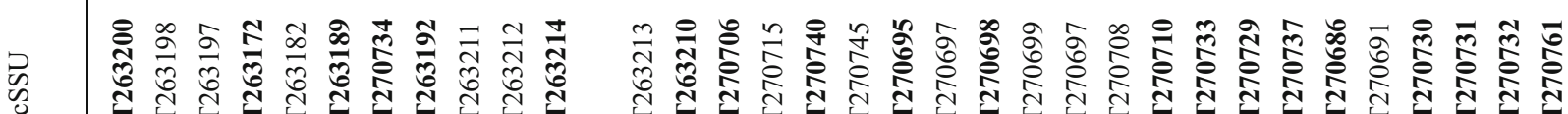

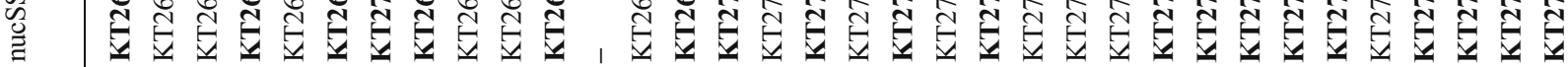

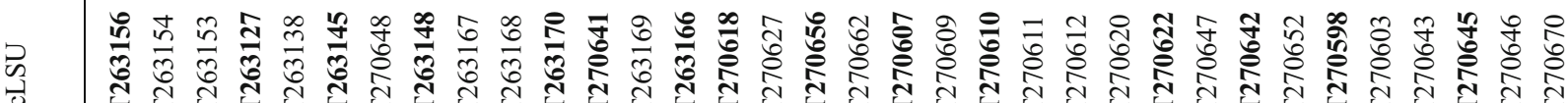

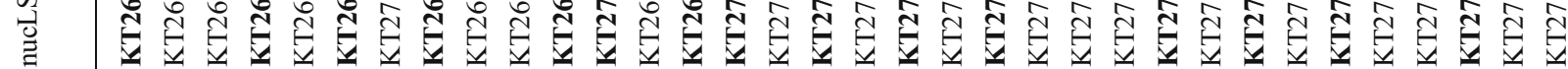

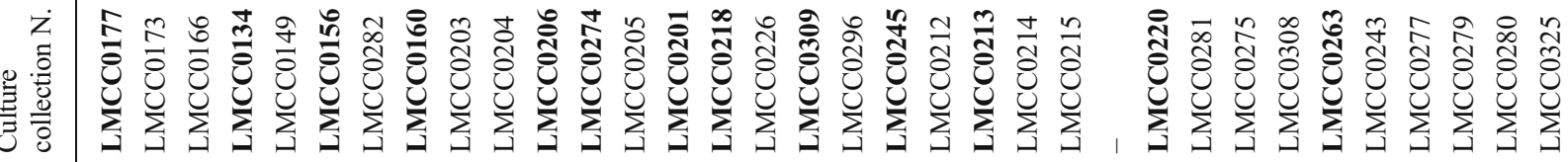
Z 冚 氖

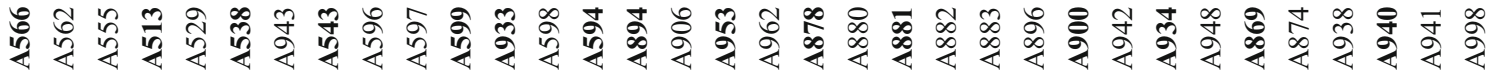

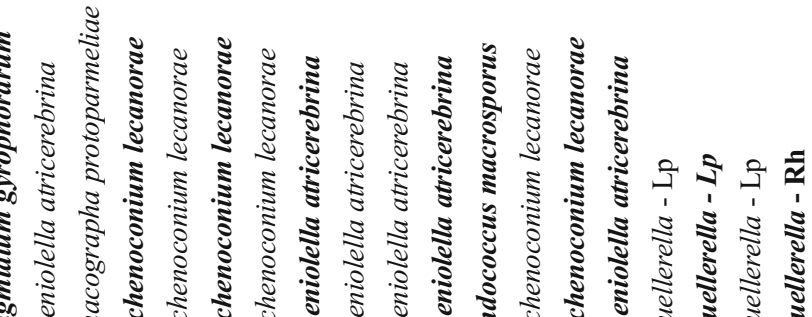

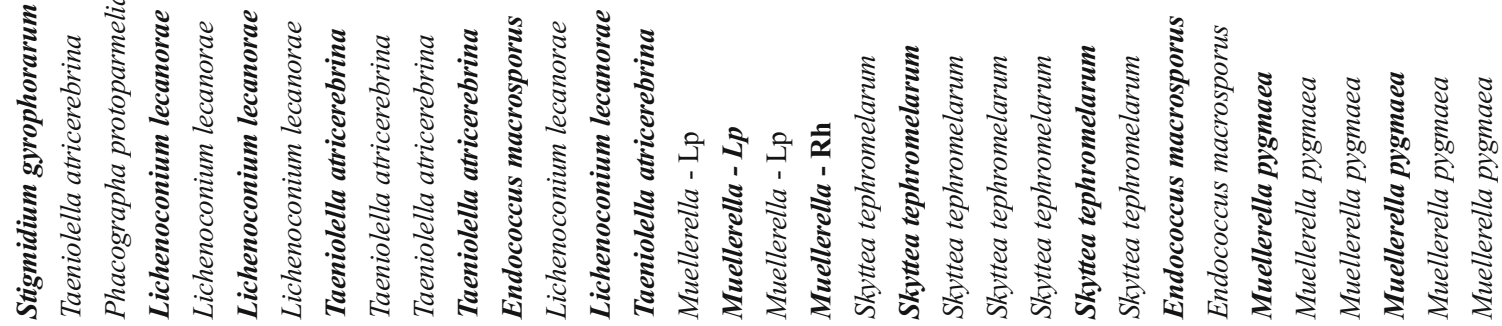

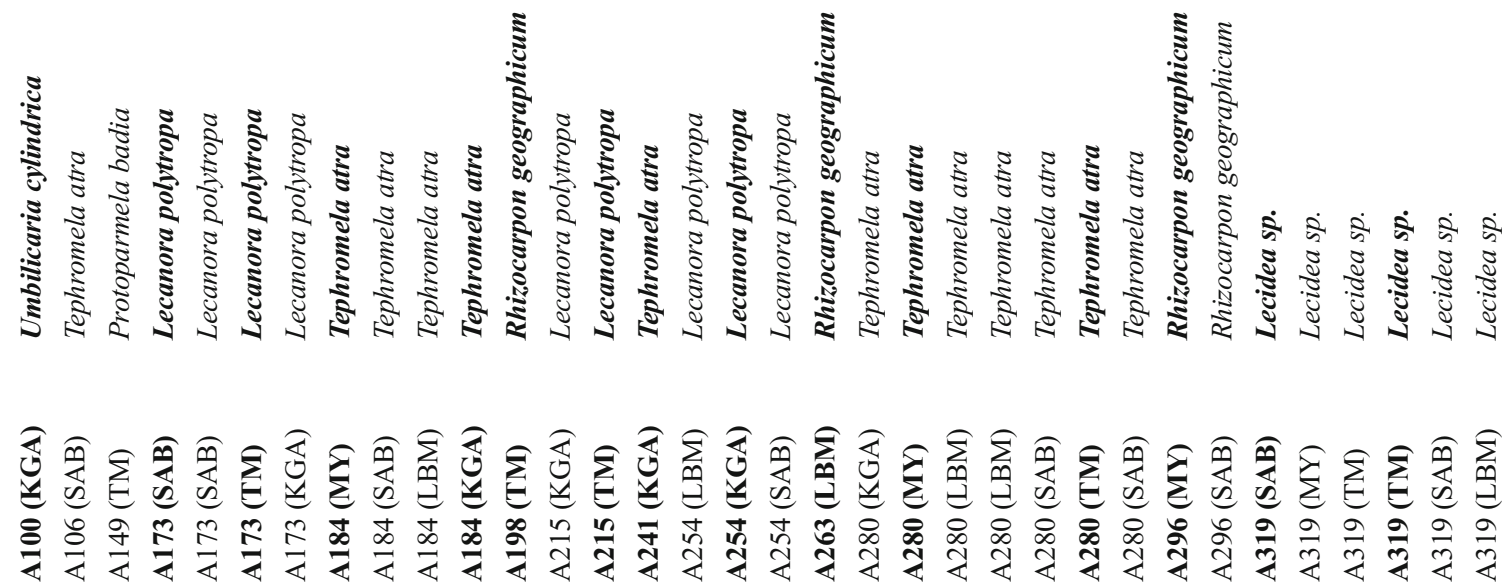




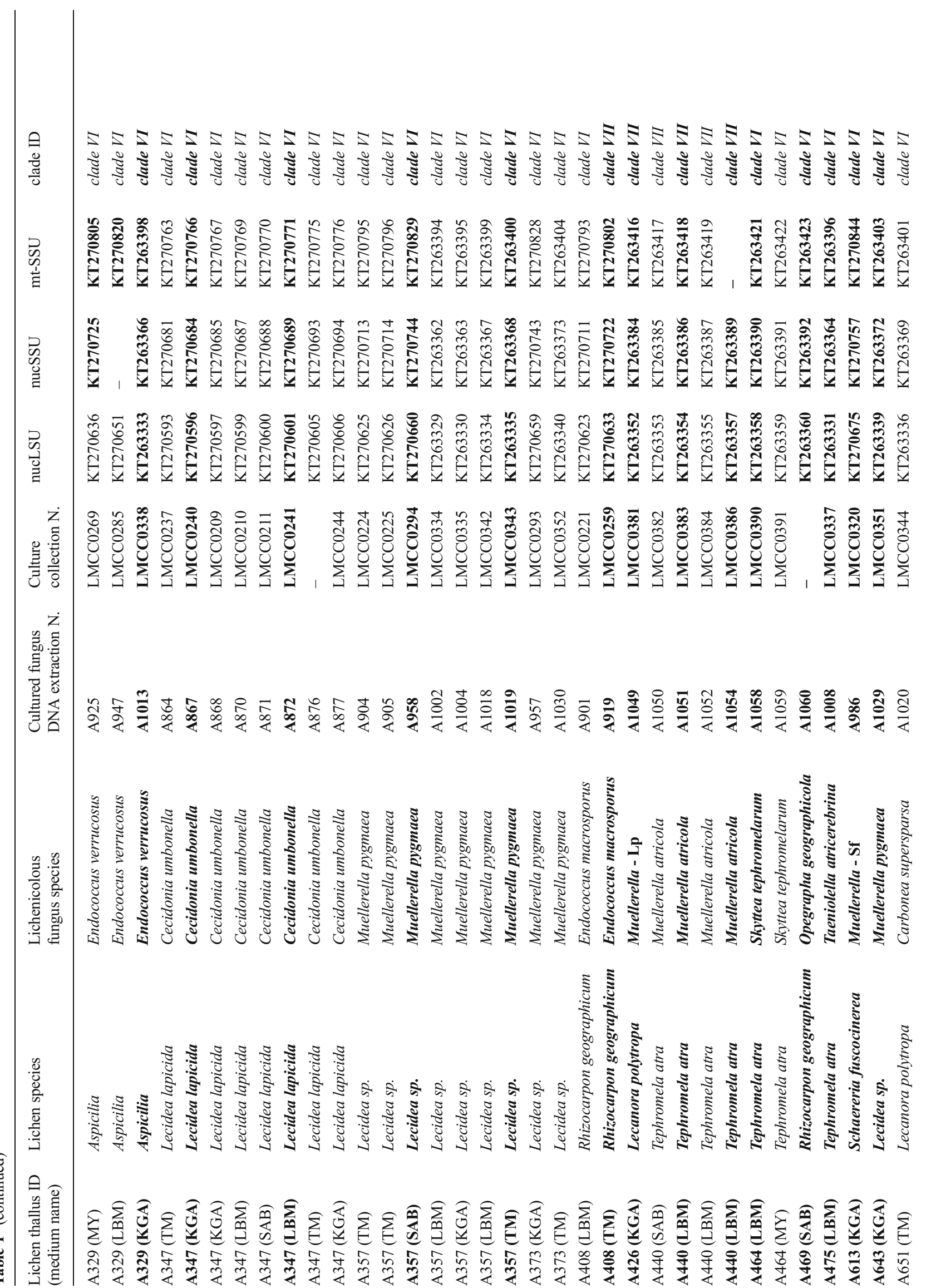




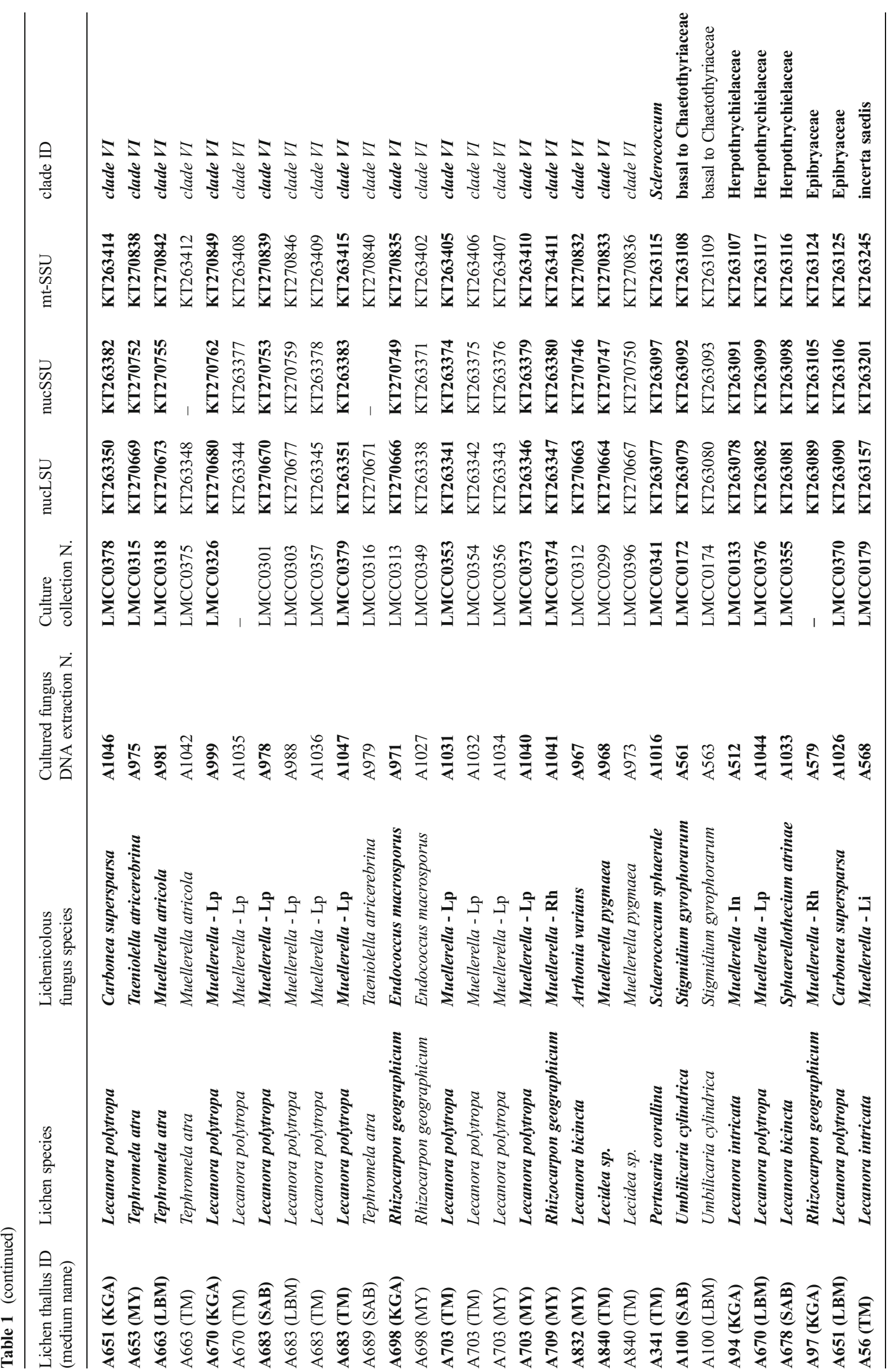




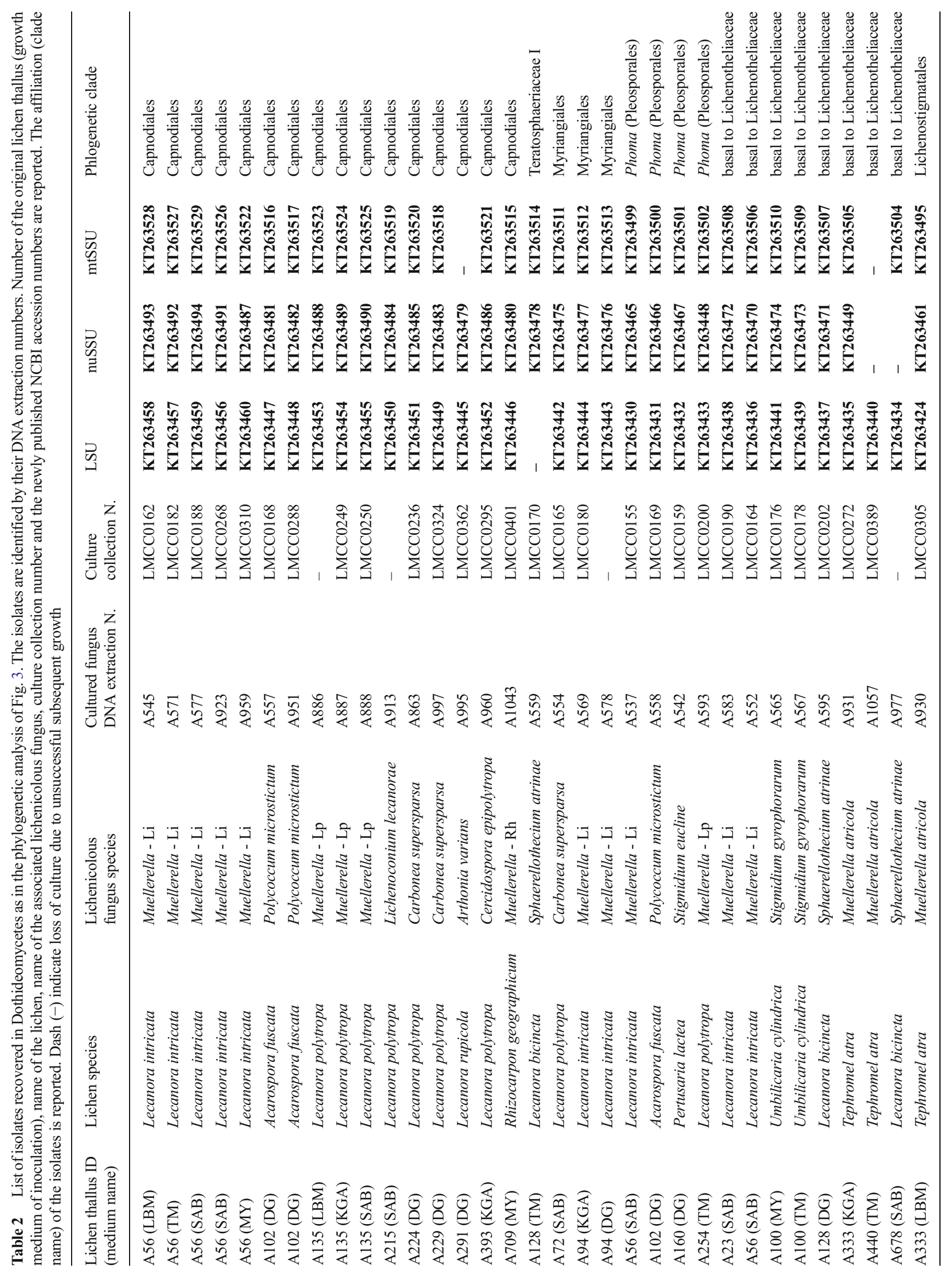


incubated in a growing chamber at $20{ }^{\circ} \mathrm{C}$, with a light-dark regime of $14: 10$ hours with light intensity of $60-100 \mu \mathrm{mol}$ photons $\mathrm{m}^{-2} \mathrm{~s}^{-1}$ and $60 \%$ humidity. After three to five months, the inocula reached about $1-3 \mathrm{~mm}$ in diameter and it was possible to subculture and to prepare them for DNA extraction, sequencing and morphological analyses. The subcultures were set on agar plates using the same growth medium where the inoculum grew successfully. The cultured strains are deposited at the University of Graz in the culture collection of the first author LM and are preserved as cryostocks.

Morphological analyses Morphological and anatomical characters of the cultured strains were analysed using standard microscopic techniques and documented with photographs. Analyses and photographs were performed on 10 month to one year old subcultures considering the following characters: form of growth, branching of the hyphae and melanization. Small fragments of the mycelia were taken; squashed sections were mounted in water and studied by light microscopy. Images were acquired with a ZeissAxioCam MRc5 digital camera fitted to the microscope. Both images of growth habit and hyphae structure were digitally processed using the CombineZM software (www.hadleyweb.pwp.blueyonder.co. $\mathrm{uk} /$ ). The photos were slightly refined in sharpness and color tone with Adobe Photoshop 7.0 and the figures were prepared with CorelDRAW X4.

DNA extraction, amplification and sequencing Small parts of the subcultured fungi were taken, transferred into $1.5 \mathrm{ml}$ reaction tubes containing sterile beads for homogenization, frozen and ground using a TissueLyserII (Retsch). The DNA was then extracted following either the C-TAB protocol of Cubero et al. (1999) or using the DNeasy Plant Mini Kit (Qiagen, Austria). The industrial kit was used for those most melanized isolates for which the C-TAB protocol failed in extracting amplifiable DNA.

The identity of the cultured fungal strains was studied with sequences of the nuclear large and partial nuclear small ribosomal subunits (nucLSU and nucSSU) and the mitochondrial small ribosomal subunit (mtSSU). The nucLSU fragment was obtained in two pieces using primers SR6R (http://www. botany.duke.edu/fungi/mycolab) and LR5 for the upstream fragment, and LR3R and LR7 (Vilgalys and Hester 1990; http://www.biology.duke.edu/fungi/mycolab/primers.htm) for the downstream fragment. The nucSSU locus was amplified using the primers NS1 (White et al. 1990) and nuSSU0852 (Gargas and Taylor 1992). The mtSSU locus was amplified with primers mtSSU1KL (Lohtander et al. 2002) and MSU7 (Zhou and Stanosz 2001) or mtSSU1 and mtSSU3R (Zoller et al. 1999). PCRs amplifications were carried out with the Illustra ${ }^{\mathrm{TM}}$ puReTaq Ready-To-Go PCR Beads (GE Healthcare, UK Limited) with a reaction volume of $25 \mu \mathrm{l}$ and a primer concentration of $0,6 \mathrm{pmol} / \mu \mathrm{l}$. The 
amplification of the genes followed touch-down PCR conditions as in previous studies (Muggia et al. 2011, 2013). PCR products were cleaned with E.Z.N.A. ${ }^{\circledR}$ Cycle Pure Kit (Omega Biotek, VWR) according to the manufacturer 's instructions. Both complementary strands were sequenced using the same PCR amplification primers by Microsynth (Sanger 3730xl from ABI, Vienna, Austria). Forward and reverse sequences were assembled into contigs and edited manually in BioEdit (Hall 1999).

Alignment and phylogenetic analyses We checked the identity of the newly generated sequences with sequences available in the GenBank database by blast similarity search (Altschul et al. 1990). Taxa which closest matched our sequences for a value not lower than $95 \%$ identity and the further closest related ones (up to $90 \%$ identity) were selected for the phylogenetic analyses. As our sequences showed closest matches with representatives of the classes Eurotiomycetes (particularly in the subclasses Chaetothyriomycetidae), Dothideomycetes, Leotiomycetes and Sordariomycetes, we prepared four different datasets representing each lineage (the multilocus sequences alignments are deposit at TreeBASE). We tried to include in each dataset the widest spectrum of taxon diversity by selecting, if possible, at least three taxa representatives of different families or orders of the four classes (Table S1, S2, S3). We based our selection also on previous phylogenetic analyses which considered the aforementioned classes (e.g. Zhang et al. 2006; Wang et al. 2006; Gueidan et al. 2008, 2011; Ruibal et al. 2009; Schoch et al. 2009; Huhndorf and Miller 2011; Untereiner et al. 2011; Muggia et al. 2013; Hyde et al. 2013; Maharachchikumbura et al. 2015; Suija et al. 2015, ). The datasets of Eurotiomycetes and Dothideomycetes were prepared in summer 2014 whereas those of Leotiomycetes and Sordariomycetes in January 2015. For this reason recent sequence data published subsequently summer 2014 by Gueidan et al. (2014) and Ertz and Diederich (2015) are not included here. For each dataset, outgroup taxa were chosen from the most closely related classes. Sequence alignments for each locus (nucLSU, nucSSU and mtSSU) and for each fungal class (Eurotiomycetes, Dothideomycetes, Leotiomycetes and Sordariomycetes,) were prepared manually in BioEdit (Hall 1999). Introns and ambiguous SNPs were removed from the alignment. For a number of specimens we were unable to generate sequences for all of the selected loci and for other taxa sequences were not available in GenBank. Therefore we present here a three-locus phylogenetic inference for the classes Eurotiomycetes and Dothideomycetes, and two-locus inferences for the classes Leotiomycetes and Sordariomycetes. The final phylogenetic analyses of the Eurothiomycetes dataset included a subset of the isolates, which were selected after having estimated a first phylogeny including all the isolates. As multiple isolates shared identical sequences, we selected for the final analyses as representatives those isolates obtained from different samples of the 25 lichenicolous fungus-lichen host associations which were grown on different media.

Combined data of different loci, either fully or partially congruent, have been commonly considered in phylogenetics (Dettman et al. 2003). We performed, therefore, as in previous studies (Kauff and Lutzoni 2002; Miadlikowska et al. 2006; Muggia Perez-Ortega et al. 2014), both single locus and combined datasets analyses. We analysed the single locus datasets with a Maximum Likelihood (ML) approach (Meson-Gamer and Kellogg 1996; Reeb et al. 2004) and the combined dataset using both maximum likelihood (ML) and Bayesian approaches. In both approaches the combined datasets were treated in partitions by genes nucLSU, nucSSU and mtSSU. The ML analyses were performed using the program RAxML v. 7.1.3 (Stamatakis et al. 2005). The GTRMIX model was applied both for the single loci and to each partition in the combined datasets (as only a single model of molecular evolution can be used across gene partitions in RAxML), and 1000 bootstrap replicates were run. The Bayesian Markov Chain Monte Carlo (B/MCMC) analyses were run in MrBayes 3.1.2 (Huelsenbeck and Ronquist 2003; Ronquist et al. 2005). The model of molecular evolution applied in the Bayesian analysis to each gene partition, the $\mathrm{GTR}+\mathrm{I}+\mathrm{G}$ model, was estimated in JModeltest v. 2.1.4 (Darriba et al. 2012) using the Akaike Information Criterion (Posada and Crandall 1998). The B/MCMC analyses were run with six chains simultaneously, each initiated with a random tree. Ten million generations for the Eurotiomycetes and Dothideomycetes datasets and five million generations for Leotiomycetes and Sordariomycetes datasets were run, respectively. Trees were sampled every 100 generations. The log-likelihood scores were plotted against generation time using Tracer 1.4 (Rambaut and Drummond 2007) to determine when the stationarity of likelihood values had been reached (e.g., the burn-in stage; Ronquist et al. 2005). Burn-in was set at half of the generations (the first 50,000 and 25,000 sampled trees for the two datasets groups respectively) and the majority rule consensus trees were calculated from the posterior samples of 50,001 and 25,001 trees, respectively. The convergence of the chains was confirmed by the convergent diagnostic of the Potential Scale Reduction Factor (PSRF), which approached 1 (Ronquist et al. 2005). The phylogenetic trees were visualized in TreeView (Page 1996).

\section{Results}

Culture isolation A total of 248 fungal cultures from 77 host lichen thalli were isolated and identified to date: 191 belong to the subclass Chaetothyriomycetidae, 36 to the class Dothideomycetes, 12 to Leotiomycetes and 9 to 
Sordariomycetes. We obtained 21 additional isolates that corresponded to the lichen mycobionts (not shown). The majority of the strains, $24 \%$, grew on TM, $22 \%$ grew on LBM, $20 \%$ on $\mathrm{SAB}, 16 \%$ on KGA, $13 \%$ on MY and $5 \%$ were isolated on DG media. Cultured mycobionts represented $2 \%$ of the grown isolates. From these cultures we obtained in total 710 new sequences: 244 for nucLSU rRNA gene, 237 for nucSSU rRNA gene and 229 for mtSSU rRNA gene (Table 1, Table 2, Table S3). The diversity of fungi isolated from lichen thalli, and which did not represent the mycobiont of the lichen symbiosis, varied among the 77 original thalli. The specificity of the isolated fungi neither correlates with the presence of any observed lichenicolous fungus nor with the identity of the lichen mycobiont. Fungi belonging to the same lineage were isolated from multiple thalli representing the same association of lichen and lichenicolous fungus, but also from the same lichen host species infected by different lichenicolous fungi (from hosts not growing in vicinity) and from other different associations of lichen and lichenicolous fungus (Tables 1, 2, S3). For example, we isolated up to five different lineages of fungi in two lichen individuals; fungi of four different lineages were isolated from only a single thallus, fungi of three different lineages were isolated from nine thalli. Fungi representing two different lineages were retrieved from 21 thalli, and fungi representing one lineage were obtained from 40 thalli.

Phylogenetic and morphological analysis of Chaetothyriomycetidae (Fig. 1, Fig. 2, Table 1 and Table S1) The phylogenetic relationships recovered in Chaetothyriomycetidae are highly congruent with previous studies of Gueidan et al. (Gueidan et al. 2008, Gueidan et al. 2011) and Diederich et al. (2013). There were no significant incongruences between single locus (not shown) and multilocus trees. The only exception is the clade of Sclerococcum sphaerale, which is placed in our multilocus reconstruction at the base of Chaetothyriomycetidae, possibly due to the availability of only the nucLSU marker (Fig. 1). In this Sclerococcum sphaerale clade we recovered the single isolate A1016. A1016 was isolated from a thallus of Pertusaria corallina infected by Sclerococcum sphaerale, and this placement seems to confirm the identity of the lichenicolous fungus. This isolated strain forms pale pinkish, compact mycelia with thin, hyaline hyphae (Fig. 2 F1-F5). Clade I is represented by six isolates (from three host species), which together with Celothelium cinchonarum are basal to the split between Verrucariales and Chaetothyriales. These isolates are similar in morphology, forming white mycelia composed by thin, hyaline hyphae, which occasionally gather in thick, plectenchymatous strands (Fig. 2 A1-A4, B1-B4). Clade II is represented by three isolates: they come from three different thalli of the same lichen host- lichenicolous fungus association (Rhizocarpon geographicum - Muellerella
Fig. 1 Multilocus phylogenetic inference of Eurotiomycetes. The ML and the Bayesian phylogenetic hypotheses were inferred from the combined dataset of nucLSU, nucSSU and mtSSU loci and corresponded in their topologies; the ML analysis is shown. Bayesian posterior probabilities ( $\mathrm{PP} \geq 95 \%$ ) and ML bootstrap support values $(\geq$ $70 \%$ ) are reported above branches (PP/bootstrap value). Newly identified clades of isolated fungi obtained from this study are highlighted in bold and are labelled as clade I to VII. Symbols indicate the different lichen host-lichenicolous fungal associations which represent the original thallus from where the fungal strains were isolated. A symbol reported multiple times for a clade indicates the number of different original thalli sharing the same lichen host-lichenicolous fungal association. Fungal life-styles are reported in parenthesis. Samples labelled with an asterisk (*) are those photographed in Fig. 2

pygmaea-Rh). These strains also present a pale pinkish mycelium, but hyphae are formed by cylindrical to semi-elliptical cells which are occasionally intercalated by roundish cells (Fig. 2 C1-C7). Two samples, A579 and A1026, are nested within Epibryaceae, the lineage formed by Epibryon and two rock-inhabiting fungi. The mycelium of these isolates is a dense aggregate of roundish, melanised cells containing inclusions, and filamentous hyphae are rarely present (Fig. 2 E1E5). Clade III represents the lichenicolous fungus Lichenodiplis lecanorae (Muggia et al. in prep.), which appears here basal to the split between the families Epibryaceae, Chaetothyriaceae and Herpotrichiellaceae. The identity of these isolates is also confirmed by the conidiomata-like structures and the conidia that are observed in the cultures (Fig. 2 D1-D4). Herpotrichiellaceae is here the most represented family of Chaetothyriales and comprises ecologically diverse fungi including human pathogens (Exophiala dermatitidis and Capronia semiimmersa), lichenicolous fungi (Capronia peltigerae and Cladophialophora parmeliae) and rock inhabiting fungi (Gueidan et al. 2008; Gueidan et al. 2011, Gueidan et al. 2014). Four newly cultured isolates are nested in this main Chaetothyriales lineage. A561 is nested in a clade with RIF and Phialophora europaea, and is morphologically similar to other previously isolated black RIFs (Fig. 2 L1-L3), having melanized hyphae frequently budding laterally and apically. Three other samples are nested in a clade with Cladophialophora parmeliae and Capronia semiimmersa. The isolates are characterized by melanized mycelia, with branching hyphae composed by elliptical, subcylindrical and subglobose cells constricted at the septa (Fig. 2 K1-K5).

In Chaetothyriales, the majority of the isolates group into subclades of a fully supported lineage sister to Chaetothyriales. Within this lineage we distinguished the main clades $I V, V, V I$ and VII (as subclade of clade VI, Fig. 1), each represented by more than four isolates. The other isolates are placed on separate smaller clades in this large assemblage of branches. Clade IV and clade $V$ include isolates from six and seven, respectively, different lichen hostlichenicolous fungus associations. Clade VI contains the majority of the isolates which come from 16 different lichen host 


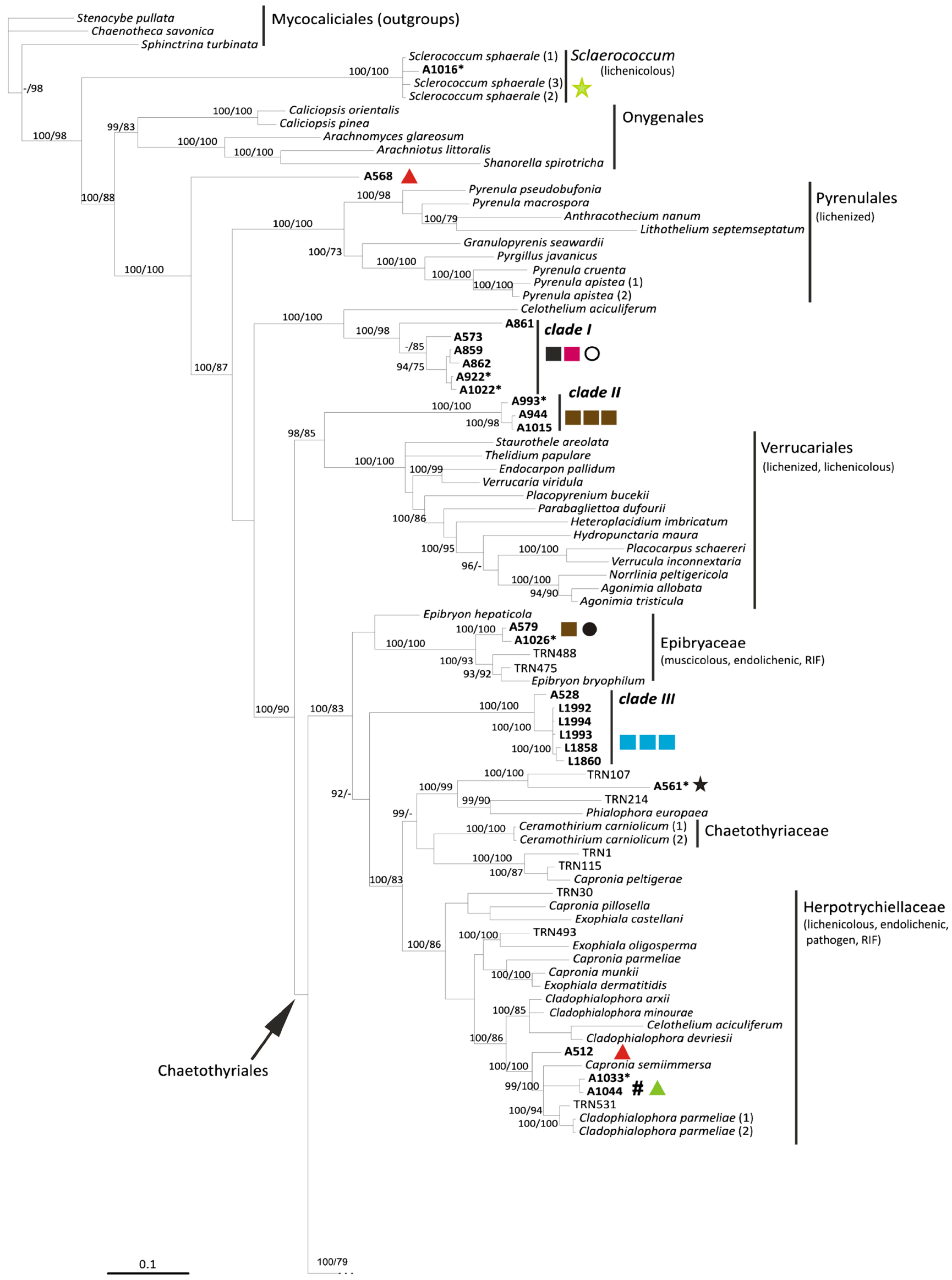




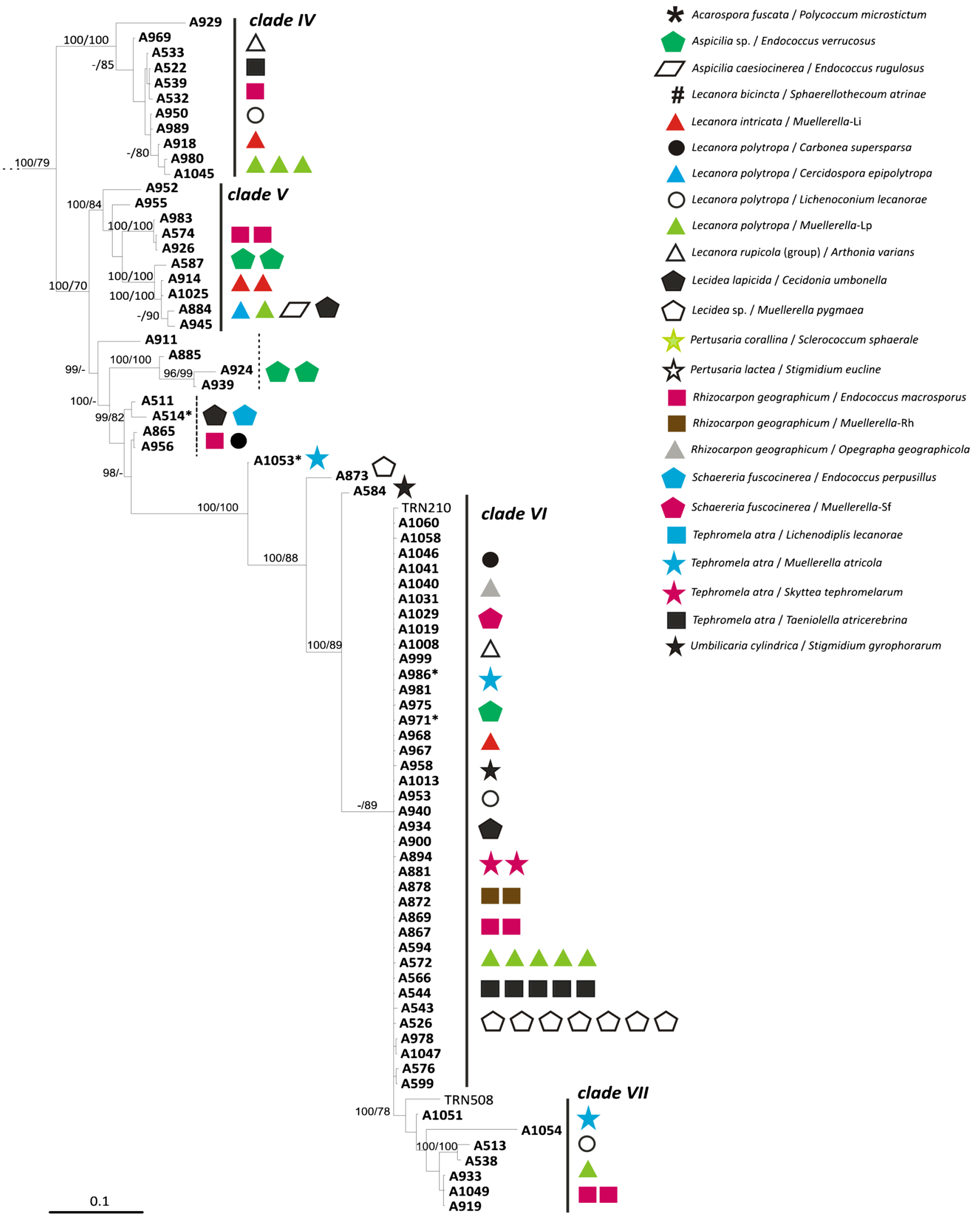

Fig. 1 (continued) 
- lichenicolous fungus associations. These include lichens infected by known but unrelated lichenicolous fungi. With the exception of few isolates, such as A514 (Fig. 2 H1-H5) and A511, which lack melanized mycelium, all the fungal strains included in this big assemblage of lineages are characterized by melanized mycelia. However, two main morphologies are observed among the strains: $i$ ) mycelia with filamentous, branching hyphae composed by cylindrical cells, usually aseptate (rarely 1 -septate), intercalating by roundish cells, $i$ ) mycelia with hyphae composed exclusively by globose, roundish cells, sometimes 1-septate, forming dense assemblages and budding.

Except for the Sclerococcum clade and the clade III, we do not find clear evidence of correspondence of certain lineages with other lichenicolous fungi infecting the lichen samples.

Phylogenetic and morphological analysis of Dothideomycetes - (Fig. 3, Fig. 4, Table 2 and Table S2) The phylogenetic relationships recovered in Dothideomycetes are highly congruent with previous studies of Ruibal et al. (2009), Lawrey et al. (Lawrey et al. 2011) Lawrey Diederich et al. 2012, Muggia et al. (2013); Hyde et al. (2013). Topological congruence was recovered between the Bayesian and the maximum likelihood analyses and among the single locus analyses. Also in Dothideomycetes the isolates are nested in clades together with fungi of diverse ecological niches and presenting different lifestyles (Fig. 3).

The isolate A930 is recovered within Lichenostigmatales, which includes lichenicolous fungi and RIFs. A930 is morphologically identical to the Lichenostigma cultures isolated by Ertz et al. (2014), presenting yeast-like, budding, melanized cells. Four isolates form a fully supported clade nested in Pleosporales. Also in Pleosporales, four further isolates group together with lichenicolous species of the genus Phoma; however they were isolated from thalli of four different lichen host-lichenicolous fungi associations and none of them showed the symptomatic presence of Phoma species. These isolates form whitish to pale pinkish mycelia, composed by hyaline hyphae distributed to form a dense aggregate (Fig. 4 A1-A5, B1-B3). Seven isolates represent a lineage sister to Lichenotheliales; these isolates originate also from four thalli representing different lichen hosts infected by different lichenicolous fungi. The isolates comprise both melanized and non-melanized fungi (Fig. 4 D1-D6 and E1-E3). Three isolates are recovered in Myriangiales, a lineage of saprobic fungi; they present white mycelium of very thin hyaline hyphae (Fig. 4 F1-F4). The single isolate A559 is recovered as a member of Teratosphaeriaceae I. The remaining isolates group as a single lineage in Capnodiales, being nested among the clades Teratosphaeriaceae I, Teratosphaeriaceae II and Mycosphaerellaceae. In this lineage we identify three subclades, even though all isolates have a similar morphology, with dark, melanized mycelia composed by suglobose to cylindrical cells with rough cell wall and sometimes constricted at the septa (Fig. 4 G1-G6, H1-H6).

Phylogenetic and morphological analysis of Leotiomycetes and Sordariomycetes (Fig. S1, Fig. S2, Table S3 and Table S4) Only 15 and nine isolates have been identified as Leotiomycetes (Helotiales) and Sordariomycetes, respectively. Within Leotiomycetes none of our isolates is closely related to the lineage Encoelioideae, where recently lichenicolous fungi were identified to belong (Suija et al. 2015). Five isolates are placed with unresolved position at the base of Leotiomycetes; one isolate is closely related to Leotia lubrica (saprotroph among mosses and plant rests, Kuo 2003) and Microglossum olivaceum (a grassland species, Fleming 2001). Eight isolates obtained from three different combinations of lichen host and lichenicolous fungus are closely related to Mitrula paludosa (a species known from swamps and bogs, Wang et al. 2005).

Three isolates are identified in Xylariales within the Sordariomycetes, one isolate is nested in Hypocreales (including insect parasitic species, mycoparasites, endophytes and saprotroph, Gazis et al. 2014), and five isolates, deriving from three different lichen host-lichenicolous fungi associations are recovered in Coniochaetales (saprotrophs, leaf and root endophytes, plant pathogens, Zhang et al. 2006). Strains of both Leotiomycetes and Sordariomycetes form pale pinkish to white mycelia (Fig. S3); melanization was seldom observed and was restricted only to localized parts of the culture (Fig S3 G).

\section{Discussion}

Rock-inhabiting alpine lichens are exposed to harsh environmental conditions, with drastic and sometimes sudden changes in temperature and hydration, as well as UV radiation. Conceivably, only fungi that tolerate such fluctuating conditions can persist or grow in lichens. In addition, these fungi must cope with the diverse and highly concentrated extracellular secondary products of their host species. We already found a surprising number of lichenicolous fungi in lichens (Fleischhacker et al. 2015), and evidence for a high number of additional, cryptically occurring fungi. Here we provided a comprehensive set of isolates of the culturable fungal fraction in lichens from an alpine habitat for a survey of their phylogenetic relationships, with special emphasis on members of Dothideomycetes and Chaetothyriomycetes.

Molecular data and the morphological analyses seem to confirm the identity of only two symptomatic lichenicolous fungal species with Eurotiomycetes. The isolates obtained from thalli infected by Sclerococcum sphaerale indeed group within the lineage Sclerococcum (Diederich et al. 2013). The formation of conidiomata and conidocells was observed in 


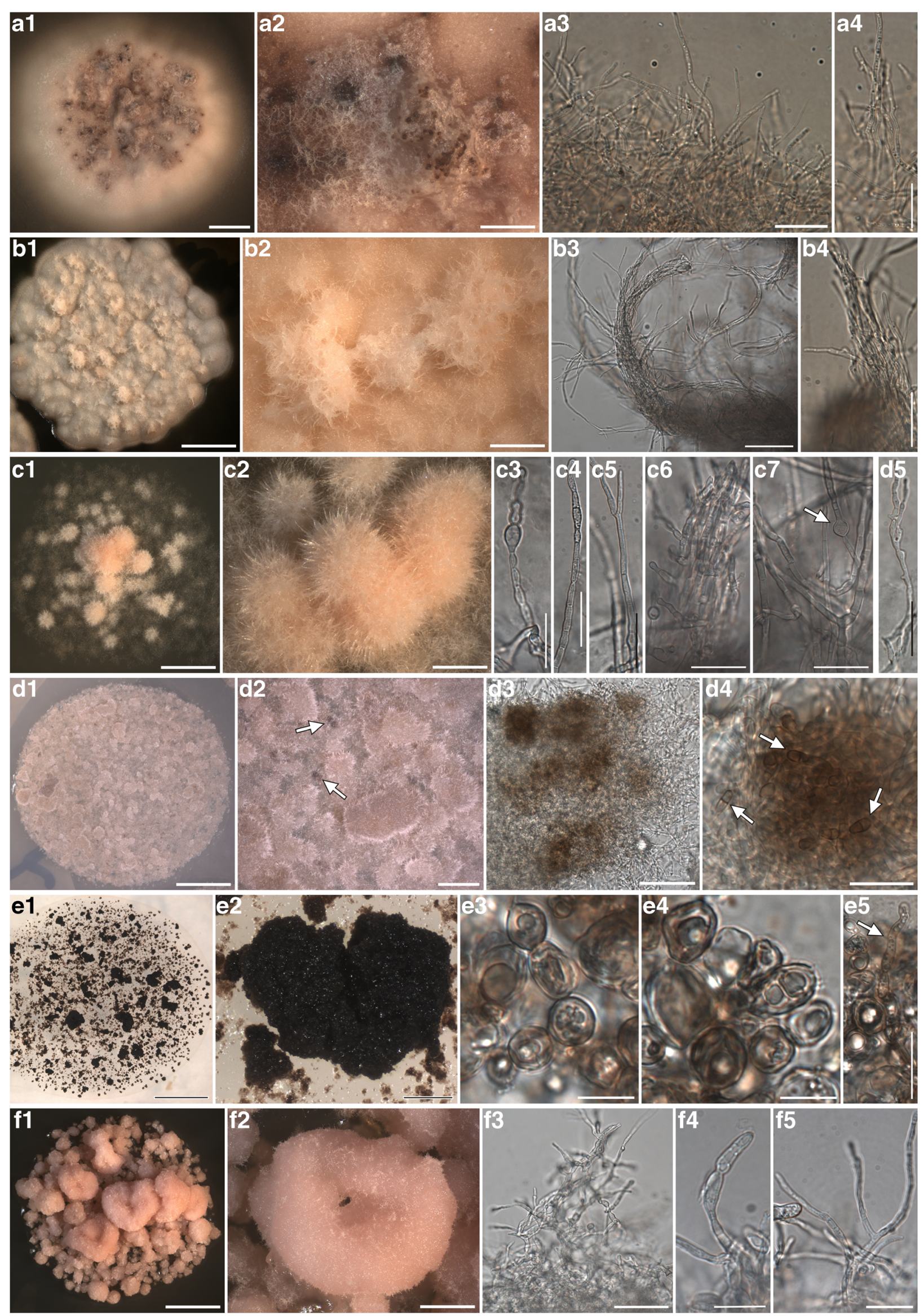


4 Fig. 2 Habitus of one year old, representative, cultured fungal strains belonging to Eurotiomycetes and included in the phylogenetic analysis of Fig. 1. Anatomical structures were photographed from squashed sections mounted in water. Samples are reported with their number and the clade to which they belong as in Fig. 1. A1-A4) A922 (clade I) - A1, A2 habitus of the mycelium; A3, A4 fine, hyaline hyphae. B1-B4) A1022 (clade I) - B1, B2 habitus of the mycelium; B3, B4 fine, hyaline hyphae, gathering in entangled, plectenchymatous strands. C1-C7) A993 (clade II) - C1, C2 habitus of the mycelium; C3-C7 hyaline hyphae with branching and globose cells intercalating with cylindrical cells. D1-D5) A528 (clade III) - D1, D2 habitus of the mycelium; D3, D4 brown cell structures containing conidia-like cells (arrow in D4); D5, hyaline hyphae. E1-E5) A1026 (Epibryaceae) - E1, E2 habitus of the mycelium; E3-E5 dense aggregate of roundish, melanised cells containing inclusions, filamentous hyphae rarely present (E5). F1-F5) A1016 (Sclerococcum) F1, F2 habitus of the mycelium; F3-F5 hyaline hyphae with branching and cylindrical, more or less elongated cells. G1-G7) A1053 (single branch, basal to clade VI) - G1, G2 habit of the melanized mycelium; G3-G7 hyphae composed by melanised, single or 1-septate cells, with numerous apical and lateral buds. H1-H5) A514 (basal to clade VI) - H1, H2 habitus of the mycelium; H3-H5 melanized hyphae with cylindrical cells, apical bud with roundish cells (H4), infrequent branching. I1-I5) A986 (clade VI) - I1, I2 habitus of the melanized mycelium; I3I5 hyphae composed by globose, roundish cells, sometimes 1-septate (I3 arrow), with thick cell wall. J1-J4) A971 (clade VI) - J1 habitus of the melanized mycelium; J2-J4 melanized hyphae with cylindrical cells intercalating with roundish cells (J3 arrow), ramifications originate both from the cylindrical and the roundish cells. K1-K5) A1033 (Herpotrichiellaceae) - K1, K2 habitus of the melanized mycelium; K3K5 melanized hyphae composed by elliptical, subcylindrical and subglobose cells constricted at the septa. L1-L3) A561 (basal to Chaetothyriaceae) melanized hyphae composed by elliptical, subcylindrical and subglobose cells constricted at the septa, frequently laterally and apically budding. Scale bars $=4 \mathrm{~mm}$ (D1, G1, H1, I1, K1), $3 \mathrm{~mm}$ (A1, B1, C1, E1, F1), 1 mm (B2, D2, I2, K2), 0.5 mm (A2, C2, E2, F2, G2, H2, J1), $50 \mu \mathrm{m}$ (B3, D3, F3, I5), $20 \mu \mathrm{m}$ (A3, A4, B4, C3-C7, D4, D5, F4, F5, G3-G7, H3-H5, I3, I4, J2-J4, K3, K4, L2, L3)

multiple cultured fungi from different thalli with infections of Lichenodiplis lecanorae. This proved the identity of the culture with the original infection of the lichenicolous hyphomycete.

Except for the above mentioned clades, we do not find clear evidence of correspondence of certain lineages with other lichenicolous fungal species infecting the lichen samples. Some of the observed lichenicolous fungi cannot be the origin of the sequenced cultures, since these belong to completely unrelated groups (e.g. Arthonia, Carbonea, Cecidonia, Opegrapha, Skyttea, Stigmidium; Ertz et al. 2009, 2014; Schmull et al. 2011; Suija et al. 2015). It is likely that the clade $I V$ and $V$, and the plenty of clades with few representatives, so far correspond to lineages of still unknown fungi which may occur widespread in lichen thalli from rocks, but are unapparent to the eye.

The present phylogenetic results also show that some of the detected fungi are closely related to lichenicolous fungi as well as to fungi known from diverse other ecological niches. Two isolates are closely related to the genus Epibryon, which was originally described as bryophilous (Döbbeler 1978). It is now emended by non-lichenized lichenicolous species
(Zhurbenko and Hafellner 1999; Sérusiaux et al. 1999), which demonstrates cross-kingdom host switches in this monophyletic genus. The host lichens of the Epibryon strain were also visibly infected by the genera Carbonea and Muellerella, respectively. Also Muellerella comprises species on bryophytes and lichens (Döbbeler and Triebel 1985), but its relationship with Epibryon requires further study. Clearly Carbonea, as a member of Lecanoraceae, is unrelated. The results suggest that Epibryon could occur also as a non-symptomatic lichen inhabitant, which agrees with the previous results of U'Ren et al. (2010), who discovered a group of fungi capable to live cryptically in both lichens and mosses. The cryptic presence of otherwise symptomatic lichenicolous fungi is also demonstrated by isolates placed with the lichenicolous lineage of the anamorph genus Phoma, and those strains which are nested with lichenicolous species of Capronia and Cladophialophora. None of these isolates, however, originated from thalli which were visibly infected by either Phoma, Capronia or Cladophialopora. The high similarity ( $>95 \%)$ that the new sequences showed with the already available Phoma sequences suggests that the isolated strain could represent closely related Phoma species.

The majority of the isolates are melanized fungi, which closely resemble previously studied rock-inhabiting fungi (RIF) and in fact are closely related to them. The presence or absence of these fungi in hosts of the same area seems to be largely unpredictable, unspecific and facultative. Rather than indicating host specificity, they seem to be broadly tolerant species whose presence might depend more on physical parameters. Nonetheless, lineage clade $V I$ (Chaetothyriales) seems to be rather ubiquitous in lichens. All selected fungi likely represent the same species occurring in many thalli and in combination with different lichenicolous fungi.

The finding of few isolates in Myriangiales, Xylariales, Hypocreales and Coniochaetales is quite interesting, as this is the first record for lichens from rocks; members of these groups are mainly biotrophic plant-associated fungi, endophytes, saprotrophs on wood and insect parasites. Fungi in Xylariales were, though, already isolated from lichen thalli from other ecological niches (Ding et al. 2009, U'Ren et al. 2012). However, no diagnostic structure hinting at these fungi have ever been observed under the microscope. Arnold et al. (2009) first suggested that fungi may live a symptomless life in lichens and coined the term 'endolichenic fungi' for such organisms. Arnold and co-authors (Arnold et al. 2009, U'Ren et al. 2010, 2012) also have studied lichens from different habitats, such as tropical forest, temperate, boreal and arctic locations. Though some of these lichens are of the same mycobiont genera as the species included in this study, Arnold and colleagues found a higher proportion of fungi in Leotiomycetes and Sordariomycetes, more closely related to lineages of plant endophytes, rather than to the lineages 

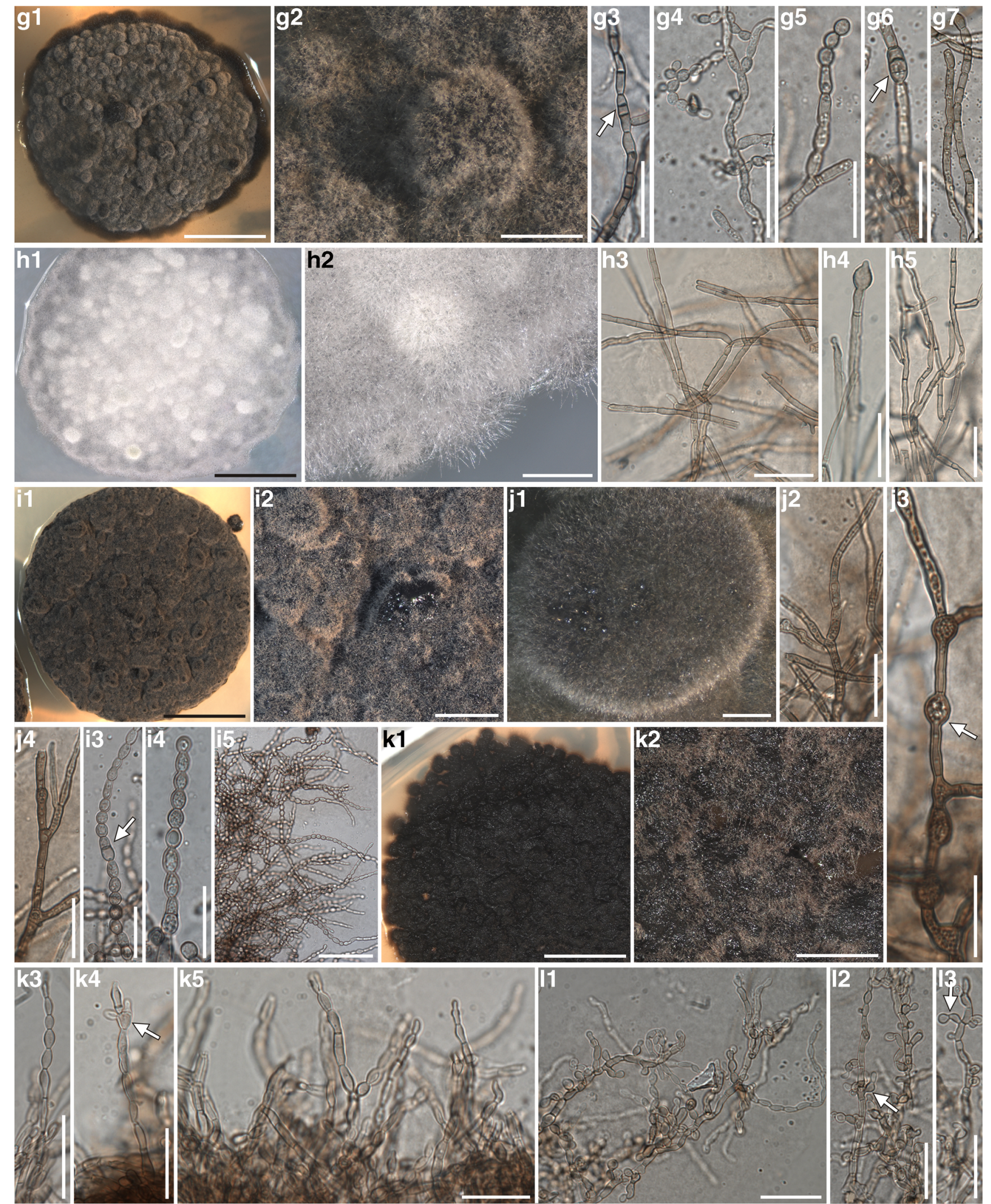

Fig. 2 (continued)

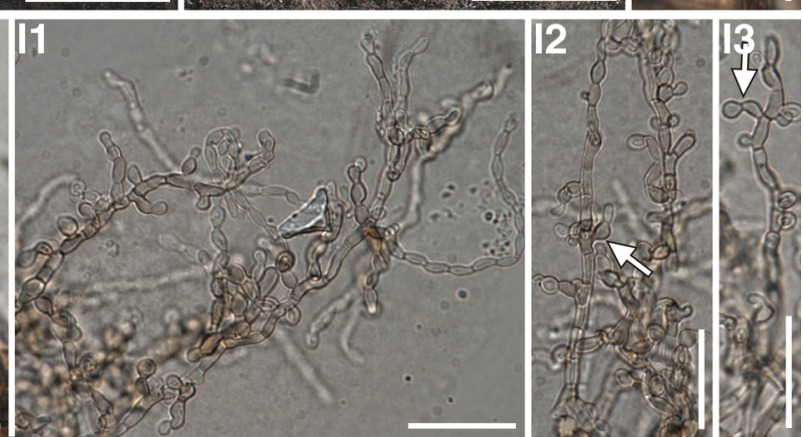




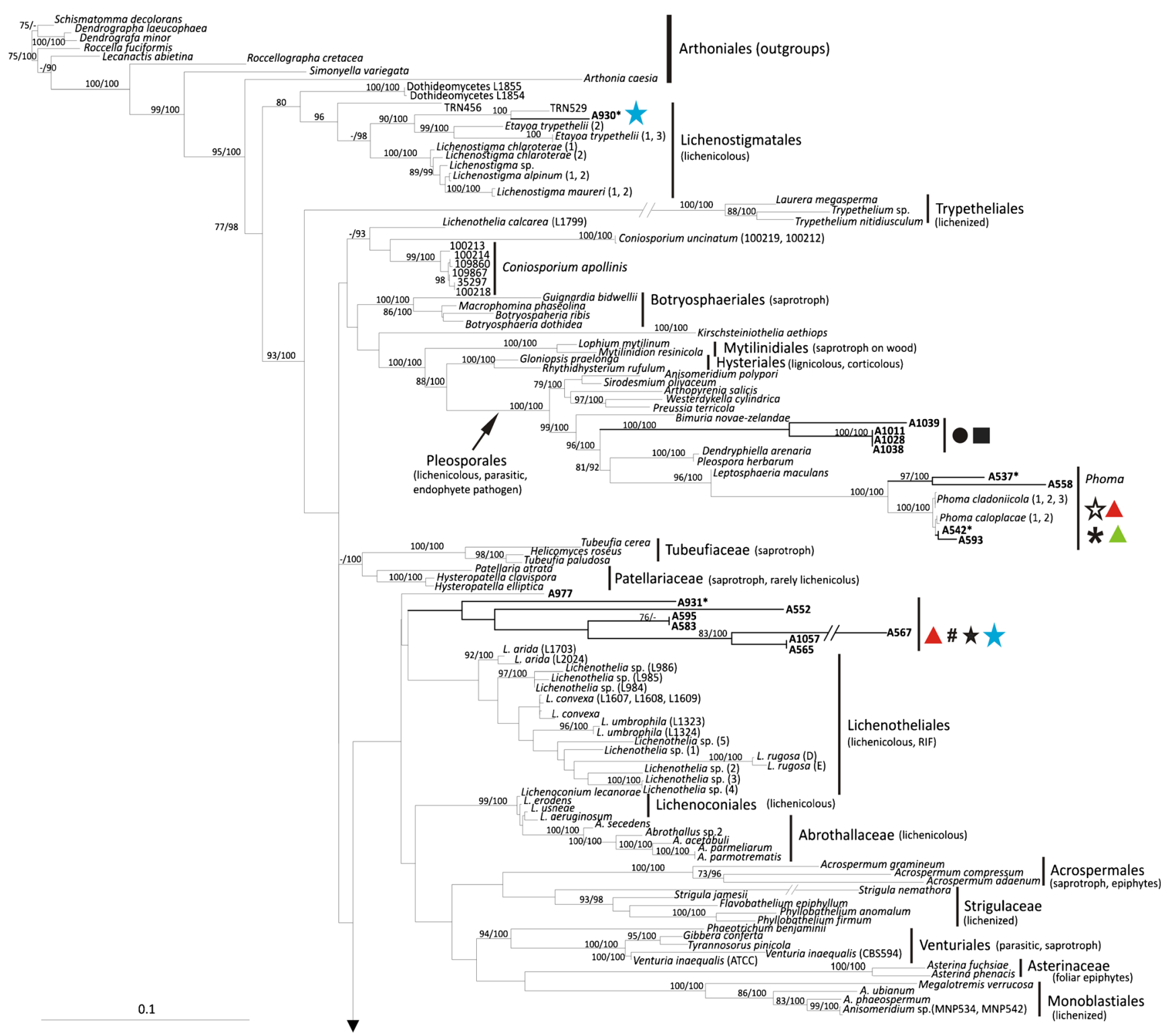

Fig. 3 Multilocus phylogenetic inference of Dothideomycetes. The ML and the Bayesian phylogenetic hypotheses were inferred from the combined dataset of nucLSU, nucSSU and mtSSU loci and corresponded in their topologies; the ML analysis is shown. ML bootstrap support values $(\geq 70 \%)$ and Bayesian posterior probabilities

predominantly found in this survey. It is likely that the taxonomic diversities recovered between the two surveys correlates with the local vegetation and geologic histories of the regions. The cryptic occurrence of fungi has been also found in different environments (Stergiopoulos and Gordon 2014), and even included plant pathogens (Malcolm et al. 2013).

We also isolated fungi which constitute two monophyletic lineages, both closely related to orders and families of lichenicolous and lichenized genera, RIF and pathogens in Dothideomycetes: the first closely related to Lichenotheliales, the second nested in Capnodiales. The first lineage is closely related to species of the genus Lichenothelia,
(PP $\geq 95 \%$ ) are reported above branches (bootstrap value/PP). Fungal isolates obtained from this study are highlighted in bold. Symbols indicate the different lichen host-lichenicolous fungal associations as reported in Fig. 1. Fungal life-styles are reported in parenthesis. Samples labelled with an asterisk $(*)$ are those photographed in Fig. 4

which are known to share multiple lifestyles on rocks (Hyde et al. 2013; Muggia et al. 2013, 2015). They dwell on bare rock surfaces, but are often found associated with free living algae also present on the rocks. Some species specialize as lichen parasites and seem to associate with the lichen photobiont (Muggia et al. 2015). Some oligotrophic fungi apparently improve their carbon supply by attaching to microscopic algae. A direct involvement of black fungi in fungalalgal interactions was earlier described as a balanced algal parasitism (Turian 1977). Several rock-inhabiting and lichen-inhabiting microcolonial fungi develop into lichenoid structures within months when co-cultured with algae 


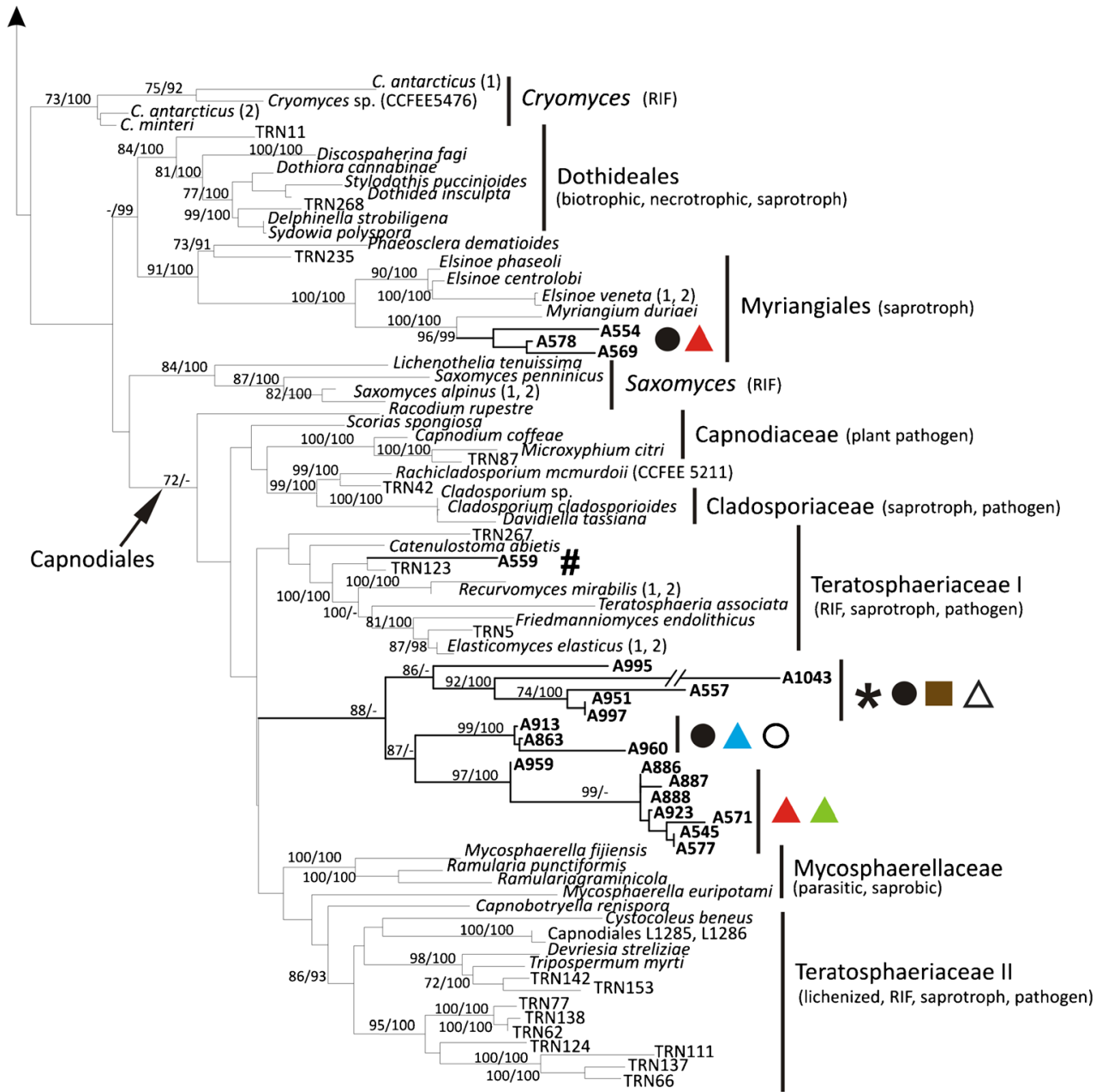

Fig. 3 (continued)

obtained from lichen thalli (Gorbushina et al. 2005; Brunauer et al. 2007). Gorbushina and Broughton (2009) showed an example with a co-culture of Nostoc and a rock-inhabiting fungus (Sarcinomyces). They observed a specific spatial arrangement of both organisms and growth alterations in the photosynthetic cyanobacteria suggested a specific interaction. Therefore black fungi that loosely associate with algae in nature might be interpreted as "lichenoids" and are considered prime forms of symbiosis (Muggia et al. 2013).

The apparent ability of black fungi to associate loosely with algae sheds an interesting light on the evolution of lichens. In fact some of the rock-inhabitants are basal to the large lichenized Ascomycete lineages Arthoniomycetes and Verrucariales (Gueidan et al. 2008; Ruibal et al. 2009). Otherwise, the lichenized life styles are scattered in various clades of Dothideomycetes (Muggia et al. 2008; Ruibal et al. 2009; Nelsen et al. 2009), where lichen thallus morphology remains generally simple. However, not all of the lineages do associate with algae or establish lichen symbioses. Some Dothideales have evolved into highly adaptable and versatile species -e.g. Aureobasidium pullulans commonly found on
Fig. 4 Habitus of one year old, representative, cultured fungal strains belonging to Dothideomycetes and included in the phylogenetic analysis of Fig. 3. Anatomical structures were photographed from squashed sections mounted in water. Samples are reported with their number and the clade to which they belong as in Fig. 3. A1-A5) A537 (Phoma) - A1, A2 habitus of the mycelium; A3-A5 hyaline hyphae with inclusions forming a dense aggregate. B1-B3) A542 (Phoma) - B1, B2 habitus of the mycelium, B3 dense aggregate of hyphae. C1-C5) A930 (Lichenostigmatales) - C1, C2 habitus of the mycelium; C3-C5 yeast-like melanised cells forming dense aggregates. D1-D6) A931 (clade sister to Lichenotheliales) - D1, D2 habitus of the mycelium; D3-D6 plectenchymatous structure of hyaline hyphae with cylindrical cells, round cells as buds at the apexes of the hyphae (arrows). E1-E3) A 567 (clade sister to Lichenotheliales) - E1 habitus of the mycelium; E2, E3 melanized hyphae composed by elliptical and subcylindrical cells constricted at the septa, laterally budding. F1-F4) A554 (Myriangiales) - F1, F2 habitus of the mycelium; F3, F4 thin, hyaline hyphae. G1-G6) A559 (Teratospaheriaceae I) - G1, G2 habitus of the mycelium; G3-G6 melanized hyphae, branching and composed by cylindrical to subglobose cells. H1-H6) A960 (clade nested in Teratosphaeriaceae) H1, H2 habitus of the mycelium, hyphae develop inside the growth medium; H3-H6 melanized hyphae, branching and composed by cylindrical to subglobose cells. Scale bars $=4 \mathrm{~mm}$ (A1, C1, D1, E1, F1, G1), 3 mm (B1), 2 mm (B2, H1), 1.5 mm (C2), 1 mm (A2, D2, F2, G2), $0.4 \mathrm{~mm}(\mathrm{H} 2), 50 \mu \mathrm{m}(\mathrm{G} 3), 40 \mu \mathrm{m}(\mathrm{C} 3, \mathrm{D} 3), 20 \mu \mathrm{m}(\mathrm{A} 3, \mathrm{C} 5$, E2, E3, F3, G4, H3-H6), $10 \mu \mathrm{m}$ (A5, B3, D4-D6, F4, G5, G6) 

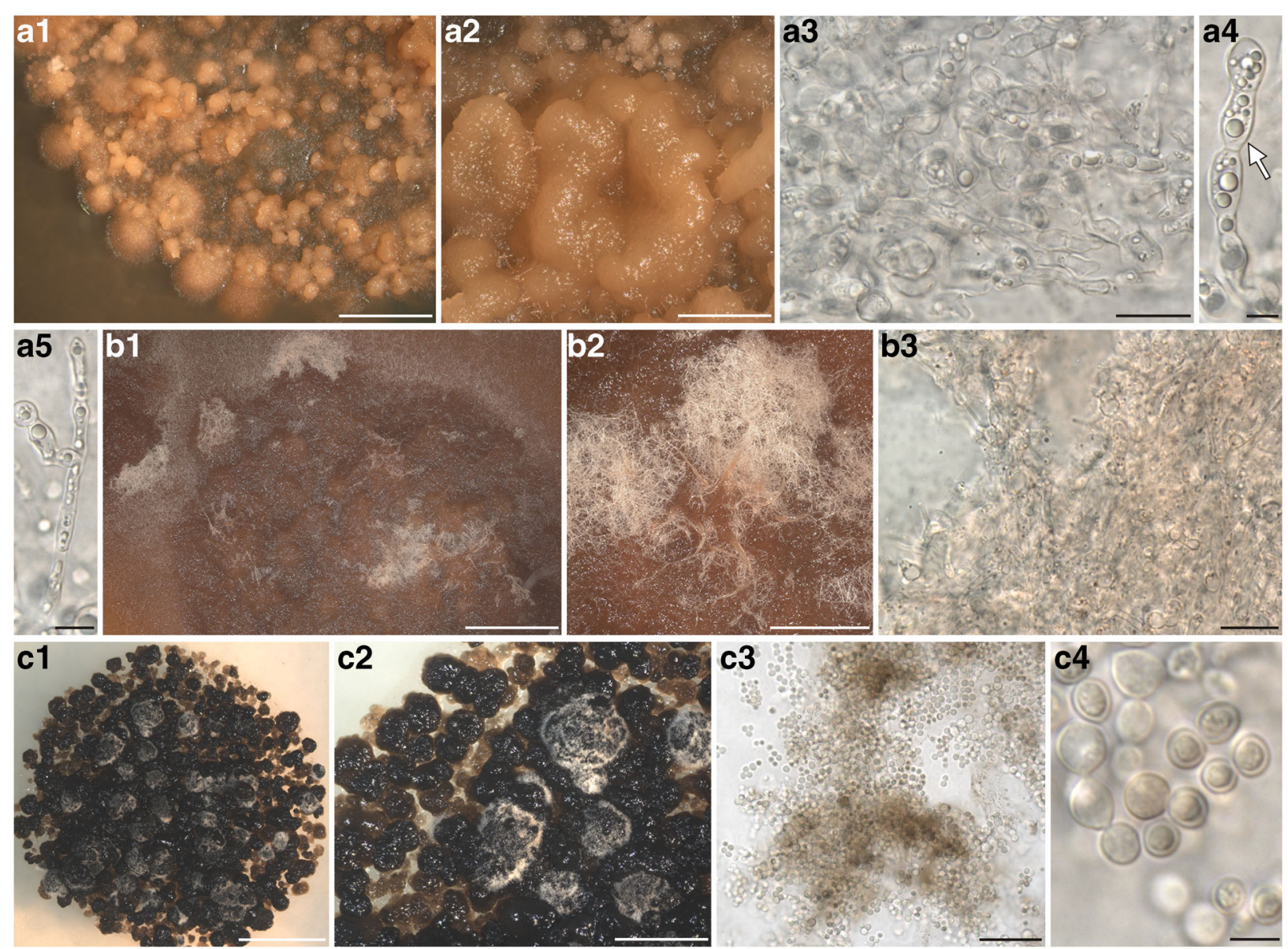

c5
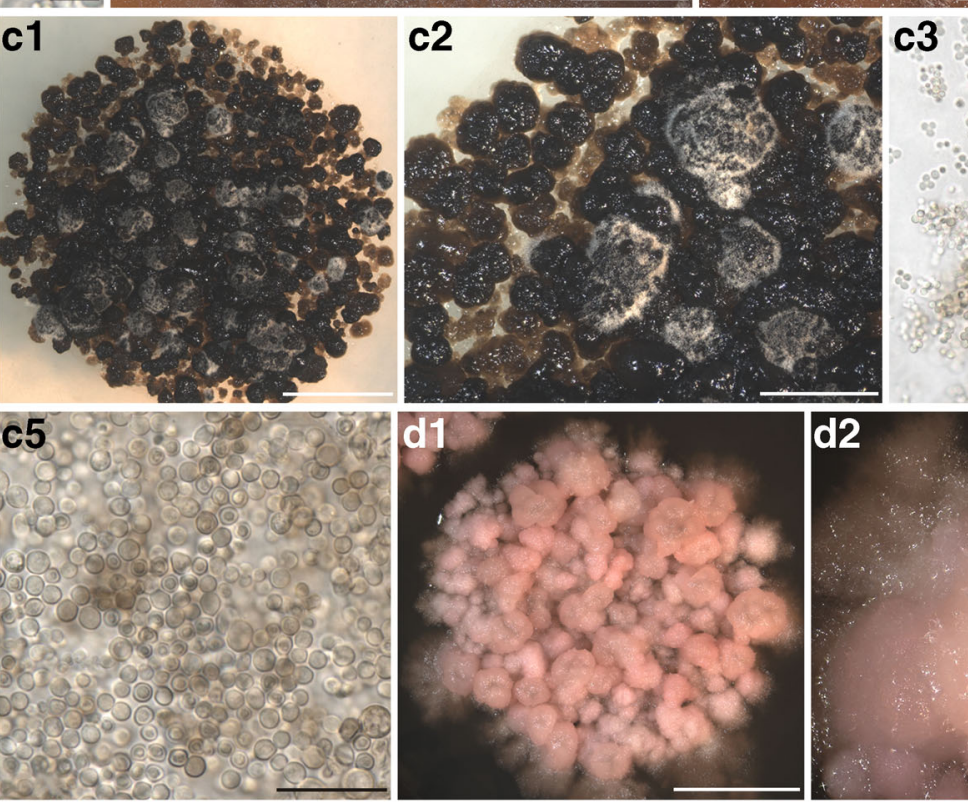

d2

c4
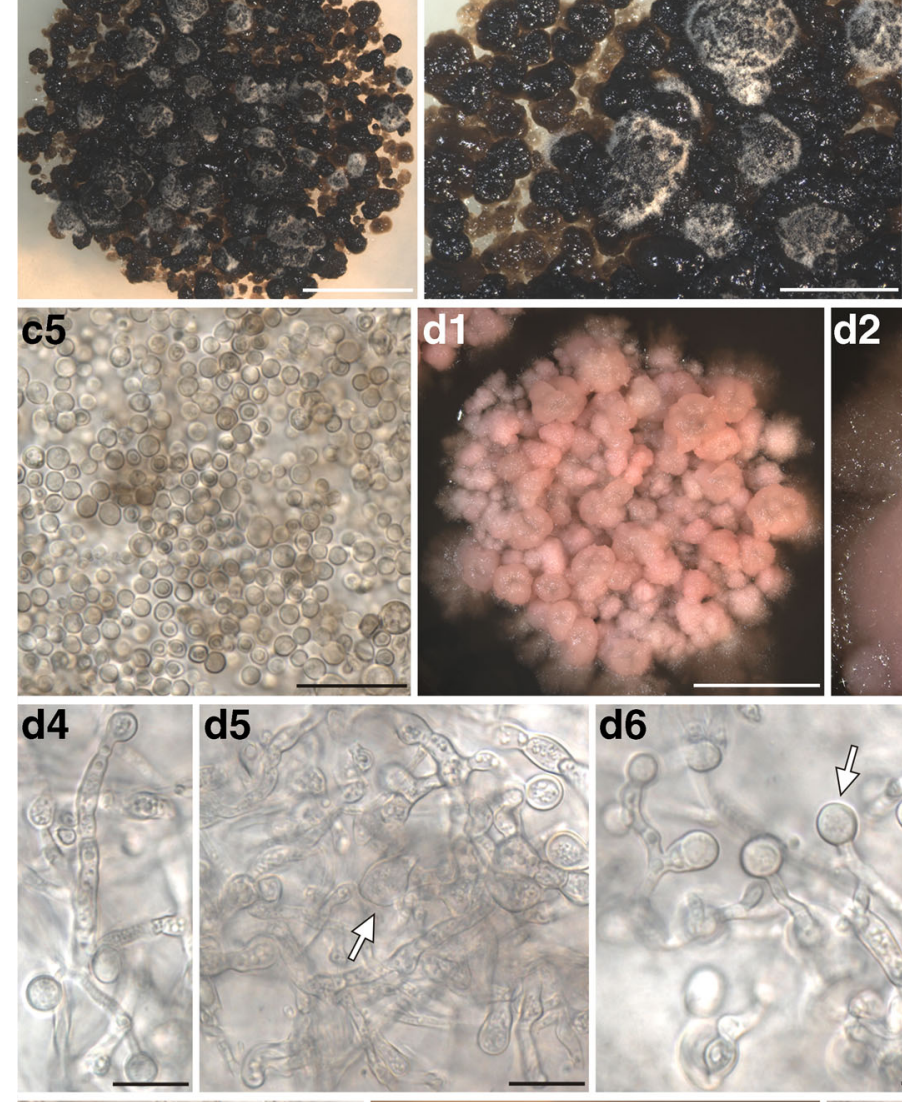

d6
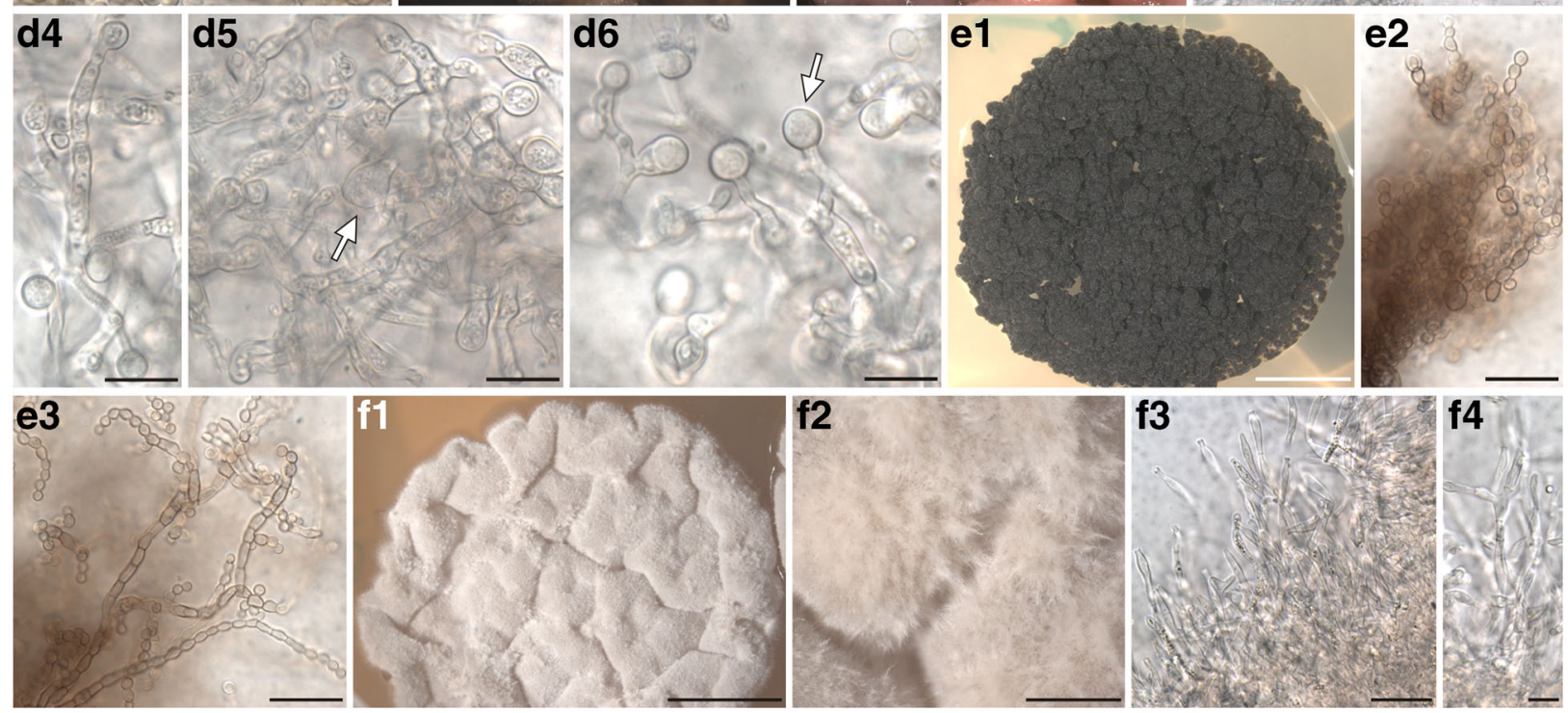

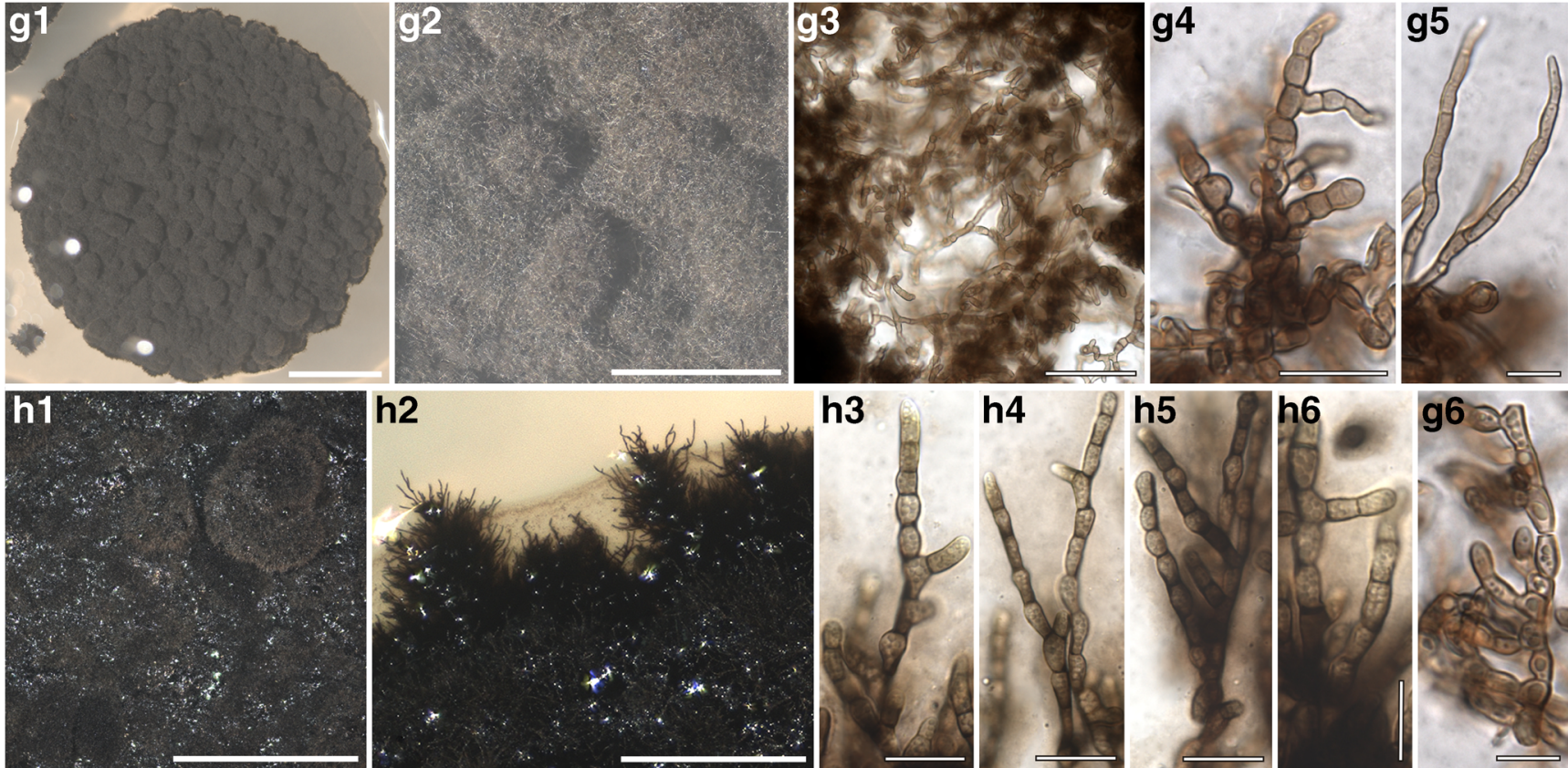

Fig. 4 (continued)

leaf surfaces of plant- but have not been found to be associated with lichens.

In our survey, fungi of unrelated lineages were recovered several times from individual lichen thalli. This may indicate that there is no competition between the different fungi, which complies with a concept of niche-sharing (Crous et al. 2009), and that the occurrence of certain lineages does not implicate the presence or absence of others. Lichen-associated fungi, which do not develop any diagnostic structure on the thallus host, use the host just for their own cryptic internal life, likely awaiting the most suitable substrate/host to propagate. Perhaps not all isolated fungi grow equally well in lichens, and we cannot exclude that some might be present as spores or small germlings, while others form mycelia networks in their hosts. We often see mycelia of melanized fungi on the lichens and expect their growth is well adapted to the poikilohydric lichen habitat. The symbiotic structures of the lichen thalli function as a shared habitat of phylogenetically diverse stress-tolerant fungi, some of which use their host as protection, while others use it as nutrition sources in otherwise hostile environments.

Acknowledgement This work was supported by the Austrian project FWF P24114-B16.

Open Access This article is distributed under the terms of the Creative Commons Attribution 4.0 International License (http:// creativecommons.org/licenses/by/4.0/), which permits unrestricted use, distribution, and reproduction in any medium, provided you give appropriate credit to the original author(s) and the source, provide a link to the Creative Commons license, and indicate if changes were made.

\section{References}

Ahmadjian V (1967) The lichen symbiosis. Blaisdell Publishing Company, Massachusetts

Altschul SF, Gish W, Miller W, Myers EW, Lipman DJ (1990) Basic local alignment search tool. J Mol Biol 215:403-410

Arnold AE, Miadlikowska J, Higgins KL, Sarvate SD, Gugger P, Way A, Hofstetter V, Kauff F, Lutzoni F (2009) A phylogenetic estimation of trophic transition networks for ascomycetous fungi: are lichens cradles of symbiotrophic fungal diversification? Syst Biol 58:283-297

Brunauer G, Blaha J, Hager A, Türk R, Stocker-Wörgötter E, Grube M (2007) Lichenoid structures in vitro of a cultured lichenicolous fungus. Symbiosis 44:127-136

Bubrick P, Galun M (1986) Spore to spore resynthesis of Xanthoria parietina. Lichenologist 18:47-49

Crous PW, Wingfield MJ, Groenewald JZ (2009) Niche sharing reflects a poorly understood biodiversity phenomenon. Persoonia 22:83-94

Cubero OF, Crespo A, Fatehi J, Bridge PD (1999) DNA extraction and PCR amplification method suitable for fresh, herbarium stored and lichenized fungi. Plant Syst Evol 217:243-249

Darriba D, Taboada GL, Doallo R, Posada D (2012) jModelTest 2: more models, new heuristics and parallel computing. Nat Methods 9:772. doi:10.1038/nmeth.2109

Dettman JR, Jacobs DJ, Taylor JW (2003) A multilocus genealogical approach to phylogenetic species recognition in the model eukaryote Neurospora. Evolution 57:2703-2720

Diederich P, Ertz D, Lawrey JD, Sikaroodi M, Untereiner MA (2013) Molecular data place the hyphomycetous lichenicolous genus Scleroccoccum close to Dactylospora (Eurotiomycetes) and S. parmeliae in Cladophialophora (Chaetothyriales). Fun Div 58: 61-72

Ding G, Li Y, Fu S, Liu S, Wei J, Che Y (2009) Ambuic acid and torreyanic acid derivatives from the endolichenic fungus Pestalotiopsis sp. J Nat Prod 72:182-186

Döbbeler P (1978) Moosbewohnende Ascomyceten I. Die pyrenocarpen, den Gametophyten besiedelnden Arten. Mitt Bot München 14:1360 
Döbbeler P, Triebel D (1985) Hepaticole Vetreter der Gattung Muellerella und Dactylospora (Ascomycetes). Bot Jahrb Syst 107:503-519

Ertz D, Diederich P (2015) Dismantling Melaspileaceae: a first phylogenetic study of Buelliella, Hemigrapha, Karshia. Labrocarpon and Melaspilea, Fun Div in press

Ertz D, Miadlikowska J, Lutzoni F, Dessen S, Raspe O, Vigneron N, Hoftetter V, Diederich P (2009) Towards a new classification of the Arthoniales (Ascomycota) based on a three-gene phylogeny focussing on the genus Opegrapha. Myc Res 113:41-152

Ertz D, Lawrey JD, Common RS, Diederich P (2014) Molecular data resolve a new order of Arthoniomycetes sister to the primarily lichenized Arthoniales and composed of black yeasts, lichenicolous and rock-inhabiting species. Fun Div 66:113-137

Fleischhacker A, Grube M, Kopun T, Hafellner J, Muggia L (2015) Community analyses uncover high diversity of lichenicolous fungi in alpine habitat. Micro Ecol 70:348-360

Fleming LV (2001) Fungi and the UK Biodiversity Action Plan: the process explained. In: Moore D, Nauta MM, Evans SE, Rotheroe $M$ (eds) Fungal conservation: Issues and solutions. Cambridge University Press, Cambridge, U.K., pp. 209-218

Gargas A, Taylor JW (1992) Polymerase chain reaction (PCR) primers for amplifying, sequencing nuclear 18S rDNA from lichenized fungi. Mycologia 84:589-592

Gazis R, Skaltsas D, Chaverri P (2014) Novel endophytic lineages of Tolypocladium provide new insights into the ecology and evolution of Cordyceps-like fungi. Mycologia 106:1090-1105

Gorbushina AA, Broughton WJ (2009) Microbiology of the atmosphererock interface: how biological interactions and physical stresses modulate a sophisticated microbial ecosystem. Ann Rev Microbiol 63:431-450

Gorbushina AA, Beck A, Schulte A (2005) Microcolonial rock inhabiting fungi and lichen photobionts: evidence for mutualistic interactions. Mycol Res 109:1288-1296

Gostincar C, Grube M, de Hoog S, Zalar P, Gunde-Cimerman N (2010) Extremotolerance in fungi: evolution on the edge. FEMS Microbiol Ecol 71:2-11

Gostincar C, Grube M, Gunde-Cimerman N (2011) Evolution of fungal pathogens in domestic environments? Fun Biol 115:1008-1018

Gueidan C, Ruibal Villaseñor C, de Hoog GS, Gorbushina AA, Untereiner WA, Lutzoni F (2008) A rock-inhabiting ancestor for mutualistic and pathogen-rich fungal lineages. Stud Mycol 61: $111-119$

Gueidan C, Ruibal C, de Hoog GS, Schneider H (2011) Rock-inhabiting fungi originated during periods of dry climate in the late Devonian and middle Triassic. Fun Biol 115:987-996

Gueidan C, Aptroot A, Silvia Caceres ME, Badali H, Stenroos S (2014) A reappreisal of orders and families within the subclass chaetothyriomycetidae (eurotiomycetes, Ascomycota). Mycol Prog 13:1027-1039

Hall TA (1999) BioEdit: a user friendly biological sequence alignment editor and analysis program for windows 95/98/NT. Nuc Ac Symp Series 41:95-98.9

Harutyunyan S, Muggia L, Grube M (2008) Black fungi in lichens from seasonally arid habitats. Stud Mycol 61:83-90

Hawksworth DL (1979) The lichenicolous hyphomycetes. — bull. Brit. Mus. Nat. Hist. Bot Ser 9:1-98

Hawksworth DL (2015) Lichenization: the origin of a fungal life style. In: Upreti DK, Divakar PK, Shukla V, Bajpai R (eds), Recent advantages in lichenology. Modern Methods and Approaches in Lichen Systematics and Culture Techniques, Volume 2, pp 1-10

Huelsenbeck JP, Ronquist F (2003) MRBAYES 3: Bayesian phylogenetic inference under mixed models. Bioinformatics 19:1572-1574

Huhndorf SM, Miller AN (2011) A molecular re-appreisal of taxa in the sordariomycetidae and a new species of rimaconus from New Zealand. Stud Mycol 68:203-210
Hyde KD, Gareth Jones EB, et al (68 authors) (2013) Families of dothideomycetes. Fun Div 63:1-313

Kauff F, Lutzoni F (2002) Phylogeny of the gyalectales and ostropales (Ascomycota, fungi): among and within order relationships based on nuclear ribosomal RNA small and large subunits. Mol Phyl Evol $25: 138-156$

Kuo M, 2003. Leotia lubrica, http://www.mushroomexpert.com/leotia lubrica.html

Lawrey JD, Diederich P (2003) Lichenicolous fungi: interactions, evolution, and biodiversity. Bryologist 106:80-120

Lawrey Diederich P, Nelsen MP, Freebury C, Van den Broeck D, Sikaroodi M, Ertz D (2012) Phylogenetic placement of lichenicolous Phoma species in the phaeosphaeriaceae (pleosporales, dothideomycetes). Fun Div 55:195-213

Lawrey JD, Diederich P, Nelsen MP, Sikaroodi M, Gillevet PM, Brand AM, Van den Broeck P (2011) The obligately lichenicolous genus Lichenoconium represent a novel lineage in the dothideomycetes. Fun Biol 115:176-187

Lilly VG, Barnett HL (1951) Physiology of fungi. McGrow-Hill, New York

Lohtander K, Oksanen I, Rikkinen J (2002) Phylogenetic study of Nephroma (lichen-forming ascomycota). Mycc Res 106:777-787

Lutzoni F, Pagel M, Reeb V (2001) Major fungal lineages are derived from lichen symbiotic ancestors. Nature 411:937-940

Maharachchikumbura SSN, Hyde DK, Gareth Jones EB, McKenzie EHC (et al. 29 authors) (2015) Towards a natural classification and backbone tree for sordariomycetes. Fun Div 72: 199-301

Malcolm GM, Kuldau GA, Gugino BK, Jiménez-Gasco Mdel M (2013) Hidden host plant associations of soilborne fungal pathogens: an ecological perspective. Phytopathology 103:538-544

Marzban G, Tesei D, Sterflinger K (2013) A review beyond the borders: proteomics of microcolonial black fungi and black yeasts. Nat Sci 5: $640-645$

Meson-Gamer R, Kellogg E (1996) Testing for phylogenetic conflict among molecular dataset in the tribe triticeae (gramiae). Syst Biol 45:524-545

Miadlikowska J, Kauff F, Hofstetter V, Fraker E, Grube M, Hafellner J, Reeb V, Hodkinson BP, Kukwa M, Lücking R, et al (2006) New insights into classification and evolution of the lecanoromycetes (pezizomycotina, Ascomycota) from phylogenetic analyses of three ribosomal RNA- and two protein-coding genes. Mycologia 98: 1088-1103. doi:10.3852/mycologia.98.6.1088

Muggia Perez-Ortega S, Fryday A, Spribille T, Grube M (2014) Global assessment of genetic variation and phenotypic plasticity in the lichen-forming species Tephromela atra. Fun Div 64:233-251

Muggia L, Hafellner J, Wirtz N, Hawksworth DL, Grube M (2008) The sterile microfilamentous lichenized fungi Cystocoleus ebeneus and Racodium rupestre are relatives of plant pathogens and clinically important dothidealean fungi. Mycol Res 112:50-56

Muggia L, Nelson P, Wheeler T, Yakovchenko LS, Tønsberg T, Spribille $\mathrm{T}$ (2011) Convergent evolution of a symbiotic duet: the case of the lichen genus Polychidium (peltigerales, Ascomycota). Am J Bot 98: $1647-1656$

Muggia L, Gueidan C, Knudsen K, Perlmutter G, Grube M (2013) The lichen conections of black fungi. Mycopathologia 175:523-535

Muggia L, Kocourkova J, Knudsen K (2015) Disentangling the complex of Lichenothelia species from rock communities in the desert. Mycologia (in press)

Nelsen MP, Lücking R, Grube M, Mbatchou JS, Muggia L, Rivas Plata E, Lumbsch HT (2009) Unravelling the phylogenetic relationships of lichenised fungi in dothideomyceta. Stud Mycol 64:135-144

Onofri S, Selbmann L, Zucconi L, de Hoog GS, de Los Rios A, Ruisi S, Grube M (2007) Fungal association at the cold edge of life. In: Seckbach J (ed) Algae and cyanobacteria in extreme environments. Springer, Dordrecht, The Netherlands, pp. 735-757 
Page RDM (1996) TREEVIEW: an application to display phylogenetic trees on personal computers. Comput Appl Biosci 12:357-358

Posada D, Crandall KA (1998) Modeltest - testing the model of DNA substitution. Bioinformatics 14:817-818

Rambaut A, Drummond A (2007) Tracer. Available from: beast.bio.ed.ac.uk/Tracer.

Reeb V, Lutzoni F, Roux C (2004) Contribution of RPB2 to multilocus phylogenetic studies of the euascomycetes (pezizomycotina, fungi) with special emphasis on the lichen-forming acarosporaceae and evolution of polyspory. Mol Phyl Evol 32:1036-1060

Ronquist F, Huelsenbeck JP, Van der Mark P (2005) MrBayes 3.1 Manual. http://mrbayes.csit.fsu.edu/mb3.1_manual.pdf.

Ruibal C, Gonzalo P, Bills GF (2005) Isolation and characterization of melanized fungi from limestone formation in Mallorca. Mycol Prog 4:23-38

Ruibal C, Gueidan C, Selbmann L, Gorbushina AA, Crous PW, Groenewald JZ, Muggia L, Grube M, Isola D, Schoch CL, Staley JT, Lutzoni F, de Hoog GS (2009) Phylogeny of rock-inhabiting fungi related to dothideomycetes. Stud Mycol 64:123-133

Schmull M, Miadlikovska J, Pelzer M, Stocker-Wörgötter E, Hoftetter V, Franker E, Hodkingson B, Reeb V, Kukwa M, Lumbsch HT, Kauff F, Lutzoni F (2011) Phylogenetic affiliations of members of the heterogeneous lichen-forming fungi of the genus Lecidea sensu zahlbruckner (lecanoromycetes, Ascomycota). Mycologia 103:983-1003

Schoch CL, Crous PW, Groenewald JZ, et al (2009) A class-wide phylogenetic assessment of dothideomycetes. Stud Mycol 64:1-15

Selbmann L, de Hoog GS, Mazzaglia A, Friedmann EI, Onofri S (2005) Fungal at the edge of life: cryptoendolithic black fungi from Antarctic desert. Stud Mycol 51:1-32

Selbmann L, Grube M, Onofri S, Isola D, Zucconi L (2013) Antarctic epilithic lichens as niches for black meristematic fungi. Biology 2: 784-979

Sérusiaux E, Diederich P, Brand AM, van den Boom P (1999) New or interesting lichens and lichenicolous fungi from Belgium and Luxembourg. Lejeunia 162:1-95

Stamatakis A, Ludwig T, Meier H (2005) RAxML-iii: a fast program for maximum likelihood-based inference of large phylogenetic trees. Bioinformatics 21:456-463

Sterflinger K, Tesei D, Zakharova K (2012) Fungi in hot and cold deserts with particular reference to microcolonial fungi. Fungal Ecol 5:453462

Stergiopoulos I, Gordon TR (2014) Cryptic fungal infections: the hidden agenda of plant pathogens. Front Plant Sci 5:506

Suija A, Ertz D, Lawrey JD, Diedetrich P (2015) Multiple origin of the lichenicolous life habit in helotiales, based on nuclear ribosomal sequences. Fun Div 70:55-72
Turian G (1977) Coniosporium aeroalgicolum sp. nov.- a dematiaceous fungus living in balanced parasitism with aerial algae. Bulletin de la Societe Botanique Suisse 87:19-24

U'Ren JM, Lutzoni F, Miadlikovska J, Arnold AE (2010) Community analysis reveals close affinities between endophytic and endolichenic fungi in mosses and lichens. Microb Ecol 60:340-353

U'Ren JM, Lutzoni F, Miadlikovska J, Laetsch AD, Arnold AE (2012) Host and geographic strcture of endophytic and endolichenic fungi at a continental scale. Am J Bot 99:898-914

Untereiner WA, Gueidan C, Orr MJ, Diederic P (2011) The phylogenetic position of the lichenicolus ascomycete Capronia peltigerae. Fun Div 49:225-233

Vilgalys R, Hester M (1990) Rapid genetic identification and mapping of enzymatically amplified ribosomal DNA from several Cryptococcus species. J Bacter 172:4238-4246

Wang Z, Binder M, Hibbett DS (2005) Life history and systematic of the aquatic discomycete Mitrula (helotiales, Ascomycota) based on cultural, morphological and molecular studies. Am J Bot 92:15651574

Wang Z, Johnston PR, Takamatsu S, Spatafora JW, Hibbett DS (2006) Toward a phylogenetic classification of leotiomycetes based on rDNA data. Mycologia 98:1065-1075

White TJ, Burns TD, Lee S, Taylor J (1990) Amplification and direct sequencing of fungal ribosomal DNA genes for phylogenies. In: Innis MA, Gelfand DH, Snisky JJ, White TJ (eds) PCR protocols, a guide to methods and applications. Academic Press, San Diego, pp. $315-322$

Yamamoto Y, Kinoshita Y, Yoshimura I (2002) Culture of thallus fragments and re-differentiation of lichens. In: Kanner I, Beckett RP, Varma AK (eds) Protocol in lichenology, culturing biochemistry, ecophysiology and use in biomonitoring. Springer, Berlin, Germany, pp. 34-46

Zakharova K, Tesei D, Marzban G, Dijksterhuis J, Wyatt T, Sterflinger K (2013) Microcolonial fungi on rocks: a life in constant drought? Mycopathologia 175:537-547

Zhang N, Castlebury LA, Miller AN, Huhndorf SM, Schoch CL, Seifert KA, Rossman AY, Rogers JD, Kohlmeyer J, Volkmann-Kohlmeyer B, Sung G (2006) An overview of the systematic of sordariomycetes based on four - gene phylogeny. Mycologia 98:1076-1087

Zhurbenko MP, Hafellner J (1999) Lichenicolous fungi from the putorana plateau, Siberian subarctic [puturana platoo (siberi subarktika) lihhenikoolne seened]. Folia Cryptogamica Estonica 34:71-79

Zoller S, Scheidegger C, Sperisen C (1999) PCR primers for the amplification of mitochondrial small subunit ribosomal DNA of lichenforming ascomycetes. Lichenologist 31:511-516 